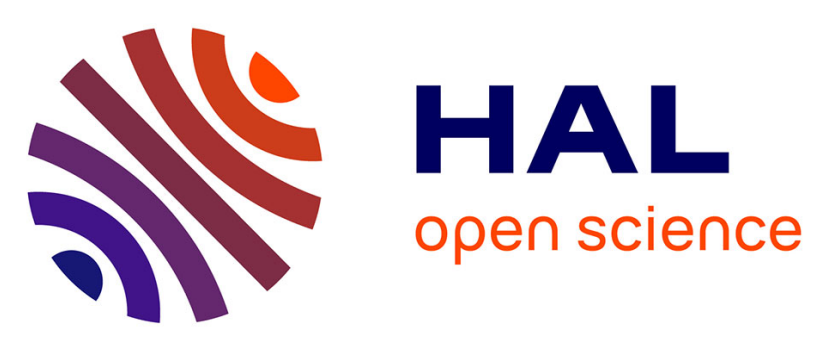

\title{
Diamond Nucleation and Seeding Techniques: Two Complementary Strategies for the Growth of Ultra-thin Diamond Films
}

Jean-Charles Arnault, Hugues Girard

\section{- To cite this version:}

Jean-Charles Arnault, Hugues Girard. Diamond Nucleation and Seeding Techniques: Two Complementary Strategies for the Growth of Ultra-thin Diamond Films. Oliver Williams. Nanodiamond, chapitre 10 (31), RSC Nanoscience \& Nanotechnology, pp.221-252, 2014, Nanoscience \& Nanotechnology Series., 978-1-84973-639-8. 10.1039/9781849737616-00221 . cea-01831889

\section{HAL Id: cea-01831889 \\ https://hal-cea.archives-ouvertes.fr/cea-01831889}

Submitted on 16 Jan 2020

HAL is a multi-disciplinary open access archive for the deposit and dissemination of scientific research documents, whether they are published or not. The documents may come from teaching and research institutions in France or abroad, or from public or private research centers.
L'archive ouverte pluridisciplinaire HAL, est destinée au dépôt et à la diffusion de documents scientifiques de niveau recherche, publiés ou non, émanant des établissements d'enseignement et de recherche français ou étrangers, des laboratoires publics ou privés. 


\section{Instructions for Book Chapter Proofs}

Please read your proof carefully, our staff won't read it in detail after you have returned it. Final responsibility for content lies with the author.

- Corrections should be marked on the PDF proof using electronic notes. Please do not send a revised Word file as we will not be able to use it.

- Correct only errors. Rewriting sections or making minor textual changes is not allowed at this stage.

- Please clearly respond to all the author queries listed on the following page, even if no corrections are required.

- If Figures need correcting, please resupply a new file at the highest possible resolution.

- Non-native English speakers: we recommend asking a native English speaking colleague to proof read all content before sending the final corrections.

\section{Please check:}

- Special characters (e.g. Greek letters/dashes/superscripts) appear correctly. This is especially important in equations.

- Figures are correct (they will be printed in colour as they appear in the proof).

- Headings and sub-headings are correctly placed.

- Copyright acknowledgements for images reproduced from another source are present and correct, and you have sent copies of the permission to the RSC.

\section{Please note:}

- This is a web quality pdf, a higher resolution file will be used for the print book.

- Corrections must not affect the pagination.

Please e-mail an annotated PDF (electronic notes) within ONE WEEK of receipt of your proof to: Oliver Williams (Oliver.Williams@astro.cf.ac.uk)

If you have any queries, please do not hesitate to contact us at: booksprodarsc.org

Books Production Team 


\section{Book Title: Nanodiamond}

Chapter 10

AQ1 Please ensure you have permission to reproduce all figures that have been previouslv published. Please supply the highest resolution available for all figure 2

AQ2 I believe citations in this section are missing as they appeared in the word as "Error: bookmark not defined". Please check whether citations shoul appear after the sentences beginning "SEM investigations (Figure 10.5)..." and "The link between structural defects..."

AQ3 Is the citation to reference 2 here erroneou

AQ4 Please provide keys for the coloured lines in Figure 10.11a

AQ5 Ref 4: please provide the place of publicatior

AQ6 Ref 7: please provide the name of the publisher and the place of publication

AQ7 Ref 43: please provide the place of publication and relevant page numbe

AQ8 Ref 59: is an update available? If pages numbers are not yet available, please provide the DOI

AQ9 The details of reference 80 and 84 are the same. Is this correct? References should onlv be listed once. Please renumber subsequent references if this is a duplicat 2

TS1 We have shortened the running head to accommodate it within the text area. Please confirm if this is ok 
CHAPTER 10

\title{
Diamond Nucleation and Seeding Techniques: Two Complementary Strategies for the Growth of Ultra-thin Diamond Films
}

\author{
J. C. ARNAULT* AND H. A. GIRARD
}

CEA, LIST, Diamond Sensors Laboratory, F-91191 Gif-sur-Yvette, France *Email: Jean-Charles.ARNAULT@cea.fr

\subsection{Introduction}

Continuous diamond films with a thickness lower than $150 \mathrm{~nm}$ grown on heterosubstrates are required for current technological applications, such as heat dissipation ${ }^{1,2}$ (silicon on diamond technology) or nano/microelectromechanical systems (NEMS/MEMS). ${ }^{3}$ The main limitation to overcome remains the low diamond nucleation densities obtained on untreated substrates, typically between $10^{3}-10^{5} \mathrm{~cm}^{-2}$ for silicon. ${ }^{4,5}$ Growth of ultrathin coalesced diamond layers requires a very high density of nucleation sites (typically $>10^{11} \mathrm{~cm}^{-2}$ ). Depending on the expected microstructure of diamond (polycrystalline, nanocrystalline or highly oriented), different experimental approaches have been developed over the last decades.

RSC Nanoscience \& Nanotechnology No. 31

Nanodiamond

Edited by Oliver Williams

(C) The Royal Society of Chemistry 2014

Published by the Royal Society of Chemistry, www.rsc.org 
Two main pathways have been explored:

(i) A nucleation pathway: ex situ or in situ substrate pre-treatments, which induce the formation of diamond nuclei, i.e., the smallest thermodynamically stable diamond crystal on the substrate during the early stages of CVD.

(ii) A seeding pathway: different surface treatments, which provide stable diamond seeds at the substrate surface that directly grow under CVD conditions.

In the nresent chapter we will focus first on diamond nucleation (section 10.2.1), pecially on the widely used bias enhanced nucleation (BEN) process (section 10.2.4). The second part will detail seeding techniques: surface abrasion using diamond particles (section 10.3.1) and how to control the homogeneous deposition of diamond nanoparticles on substrates (section 10.3.2). To conclude, we will draw a comparison between BEN and seeding approaches to underline their complementarities in terms of substrates (properties and size), diamond film adhesion and microstructure of the diamond films grown.

\subsection{Diamond Nucleation}

\subsubsection{What is Nucleation?}

Nucleation is the formation of the smallest thermodynamically stable aggregate, which is called a nucleus. Indeed, below this critical size, aggregates have significant probability to disappear, while bigger aggregates can only grow.

For homogeneous nucleation, i.e., direct condensation, no external system, such as a surface, is involved. For diamond, homogeneous nucleation could occur directly within the gas phase durin (C) emical deposition (CVD). The critical size could be obtained considering tre capillary theory of Volmer and Weber. ${ }^{6}$ The supersaturation rate is defined as the ratio of the real vapor pressure to the equilibrium vapor pressure. For an aggregate containing $n$ atoms and a positive supersaturation rate, the free enthalpy $\Delta G_{n}$ could be expressed as the sum of the bulk and surface terms:

$$
\Delta G_{n}=n \Delta \mu_{\mathrm{c}}+\sum_{\mathrm{j}=1}^{\mathrm{k}} \sigma_{\mathrm{j}} \cdot S_{\mathrm{j}}
$$

with $\Delta \mu_{\mathrm{c}}$ the difference of atomic free enthalpy and $\sigma_{\mathrm{j}}$ the surface tension of the j crystal facet of surface $S_{\mathrm{j}}$.

The critical size $n^{*}$ corresponds to the maximum value of $\Delta G_{n}$. Addition of atoms to the stable aggregate leads to a decrease of the free enthalpy, i.e., to thermodynamically stable aggregates. 
In most cases diamond deposition is taking place on a surface. It corresponds to heterogeneous nucleation. Here, the interface $\mathrm{AB}$ between an aggregate (A) on a surface (B) should be taken into account via its interfacial energy $\gamma_{\mathrm{AB}}$ via the Dupray relation. ${ }^{7}$ This implies two additional terms for the free enthalpy $\Delta G_{n}: \Omega$

$$
\Delta G_{n}=n \Delta \mu_{\mathrm{c}}+\sum_{\mathrm{j}=1}^{\mathrm{k}-1} \sigma_{\mathrm{j}} \cdot S_{\mathrm{j}}+\gamma_{\mathrm{AB}} S_{\mathrm{AB}}-\sigma_{\mathrm{B}} S_{\mathrm{AB}},
$$

with $\Delta \mu_{\mathrm{c}}$ the difference of atomic free enthalpy, $\sigma_{\mathrm{j}}$ the surface tension of the crystallographic $\mathrm{j}$ facet of surface $S_{\mathrm{j}}, \gamma_{\mathrm{AB}}$ the interfacial energy, $S_{\mathrm{AB}}$ the interface surface and $\sigma_{\mathrm{B}}$ the surface tension of the substrate B.

\subsubsection{Diamond Homogeneous Nucleation}

Homogenous nucleation, i.e., the formation of diamond nuclei in a gas phase, was predicted by classical nucleation theory ${ }^{9}$ and diamondoids from the adamantane family ${ }^{10}$ were first proposed as precursors. However, they were finally found to be highly unstable under CVD plasma conditions ${ }^{11}$ and graphite precursors, like polycyclic aromatics, may constitute possible precursors due to their higher stability. ${ }^{12}$ In particular cases, a few experimental studies reported diamond formation in the gas phase ${ }^{13-15}$ and some hexagonal diamond was even collected. ${ }^{15}$ More recently, homogeneous diamond nucleation was reported at low pressure $\left(<10^{2}\right.$ Pa compared to $10^{3}-10^{4} \mathrm{~Pa}$ for conventional CVD) and a low electron temperature $(2.6 \mathrm{eV}$ instead of $5 \mathrm{eV}$ ) using surface microwave plasma (MPCVD) for diamond growth on plastic substrates at a temperature lower than $100{ }^{\circ} \mathrm{C} .{ }^{16}$ Transmission electron microscopy (TEM) investigations have demonstrated the presence of nanometric diamond crystals, probably formed in the gas phase (Figure 10.1). These findings are supported by calculations, which predicted suitable plasma conditions. ${ }^{17,18}$

A recent article has review the state-of-art of diamond homogenous nucleation models from bulk liquid. These calculations may explain why the homogeneous diamond nucleation is likely in carbon-rich stars and planets, such as Uranus and Neptune. ${ }^{19}$ Indeed, the presence of $5 \mathrm{~nm}$ diamond particles in meteorites was first reported by Lewis et al. ${ }^{20}$ The Raman signature of nanodiamonds extracted from the meteorite Orgueil (averaged size of $2-3 \mathrm{~nm}$ ) was then compared to synthetic $5 \mathrm{~nm}$ diamonds. ${ }^{21}$ Finally, nanometric diamond particles $(5-10 \mathrm{~nm})$ were also formed by detonation synthesis under non-equilibrium thermodynamics conditions. ${ }^{22}$

\subsubsection{Diamond Heterogeneous Nucleation}

\subsubsection{Models and Theory}

A review of models was reported in 1995. The reaction involved in the formation of a critical diamond nucleus was analyzed in detail. 


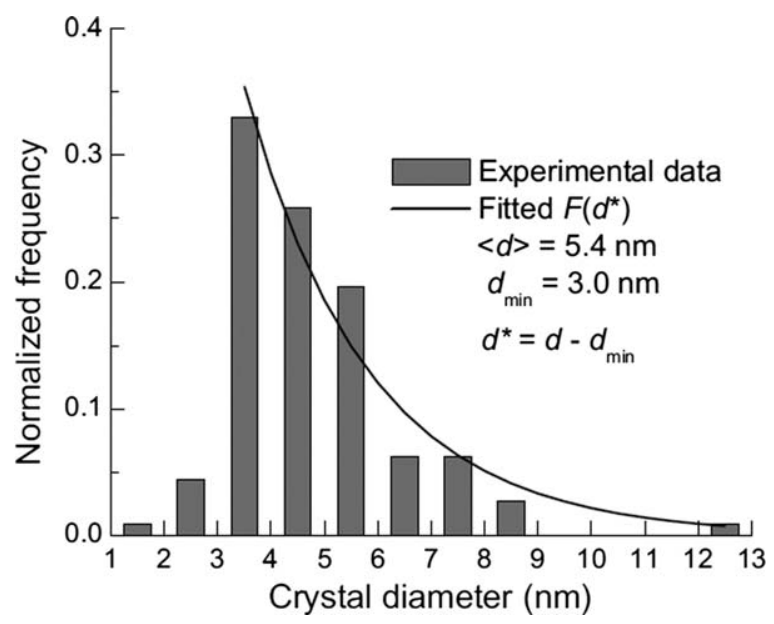

Figure 10.1 Size distribution of diamond crystals from TEM observations. The minimum size is $3 \mathrm{~nm} .{ }^{16}$

A computational method to obtain the size distribution function was checked with both experimental distribution functions and nucleation densities extracted from scanning electron microscopy (SEM). ${ }^{23}$ Avrami formalism was developed to model diamond nucleation and growth. ${ }^{24}$ The ultimate aim was to describe, by means of rate equations, the kinetics of film formation over the whole range of $q$ rerage. Kinetic quantities were calculated such as i) the film perimeter; the evolution of the fractional surface covered by the film (through the $\mathrm{KJMA}^{\dagger}$ model ${ }^{25-28}$ ) and iii) the behavior of the island density during the growth up to the closure of the film (when direct impingement of carbon species from the gas phase to the surface cannot be neglected). More recently, the particle size distribution function was analyzed in terms of particle volume rather than, as usually done, the diameters of particles. ${ }^{29,30}$ The model was then employed to describe experimental data. ${ }^{31}$

\subsubsection{Experimental Observations of Diamond Nuclei}

Theoretically, diamonds of 3-5 $\mathrm{nm}$ in size are more stable than graphite. ${ }^{32,33}$ As previously shown, the critical size is substrate dependent (via the interfacial energy $\gamma_{\mathrm{AB}}$ and the surface tension $\sigma_{\mathrm{B}}$, eqn 10.2). In the literature experimental observations of very small diamond nuclei have been reported. For example, diamond nanocrystals (2-6 nm) were observed by high resolution transmission electron microscopy (HRTEM) grown directly on Si surfaces $^{34,35}$ (Figure 10.2) or on a silicon carbide interlayer, ${ }^{36}$ sometimes even embedded in an amorphous carbon matrix. ${ }^{37}$ For diamond nucleation

${ }^{\dagger}$ This model corresponds to the one initially developed by Kolmogorov and, independently, two years later, by Johnson and Mehl, and Avrami. It is called the KJMA model. 


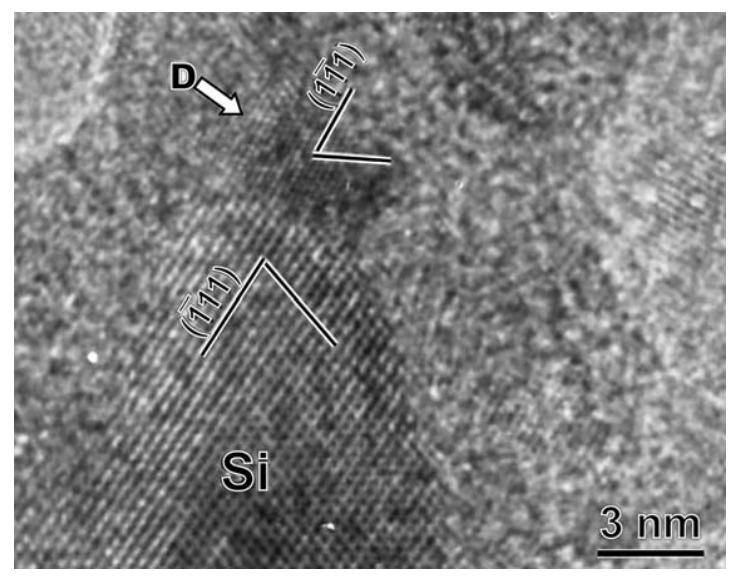

Figure 10.2 $\begin{aligned} & \text { HRTEM } \\ & \text { silicon. }\end{aligned}$
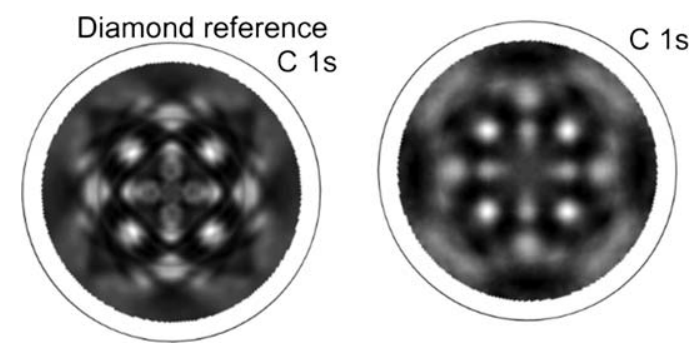

Figure 10.3 2 pD patterns of a diamond reference and after nucleation on

on iridium, it was impossible to observe the smallest diamond nuclei using HRTEM before short CVD growth. ${ }^{38}$ Nevertheless, the diamond signature was extracted from X-ray photoelectron diffraction (XPD) ${ }^{39,40}$ (Figure 10.3) and high resolution electron energy loss spectroscopy (HREELS). ${ }^{41}$ Indeed, these two techniques are particularly sensitive to the order at short distances.

\subsubsection{Surface Mechanisms Competing with Heterogeneous Diamond Nucleation}

Since 1980, CVD diamond has been grown on numerous heterosubstrates. ${ }^{4,42}$ In some studies heteroepitaxial growth was achieved. ${ }^{43}$ This research field will be further discussed (section 10.2.4). The intrinsic reactivity of each heterosubstrate, with energetic species coming from the CVD plasma, is an essential parameter to consider. Indeed, interactions with the reactive species may induce surface or subsurface mechanisms, which strongly influence the nucleation pathways. As a consequence, the nature of the 
diamond/substrate interface could strongly differ. Let us illustrate this with heterosubstrates exhibiting very different reactivities toward CVD plasma.

A previous review has focused on the mechanisms taking place on silicon, ${ }^{44}$ like surface etching by atomic hydrogen and silicon carbide formation, and their consequences on diamond nucleation. A sequential XPS analysis performed in a UHV set-up connected to a MPCVD reactor has shown the removal of the native silicon oxide after $\mathrm{H}_{2} / \mathrm{CH}_{4} \mathrm{CVD}$ exposure of 5 min while a silicon carbide $2.5 \mathrm{~nm}$ thick overlayer is stabilized. ${ }^{45}$ With nickel or platinum substrates, the high carbon solubility ${ }^{46}$ leads to carbon dissolution into the substrate under CVD plasma and induces the formation of a graphitic overlayer before diamond nucleation can occur. ${ }^{47-51}$ Under CVD conditions, carbon graphitic nanostructures, like carbon onions, were formed on copper surfaces. ${ }^{52}$ More recently, this specific behavior was used to grow high quality CVD graphene layers. ${ }^{53}$

On the other hand, cubic silicon carbide (100) oriented surfaces were found to be very inert towards CVD exposure. Their surface stoichiometry within the first atomic planes was weakly modified. A silicon rich surface (three reconstructed planes) is slightly etched under $\mathrm{H}_{2} / \mathrm{CH}_{4}$ plasma and becomes silicon-terminated (one reconstructed plane), as shown by low energy electron diffraction (LEED) (Figure 10.4) and XPS investigations. ${ }^{54}$ These modifications of the extreme surface were, however, sufficient to significantly influence diamond nucleation. ${ }^{55}$ Lastly, on iridium, a weak amount of carbon may be dissolved into the substrate during plasma exposure, ${ }^{56}$ which could segregate at the surface after cooling. The formation of furrows along $<110>$ directions at the iridium (100) surface has been observed. ${ }^{57,58}$ According to high resolution SEM investigations, these surface structures are closely related to the formation of oriented diamond nucleation $^{59}$ (see section 10.2.4).

\subsubsection{Role of Structural Defects on Heterogeneous Nucleation}

A few papers have discussed the role of extended defects on diamond nucleation. Nevertheless, it is a well-established fact that surface defects play a fundamental role on heterogeneous nucleation processes. ${ }^{60,61}$ Defect needed to induce the nucleation process by lowering the enthalpy of $n$ i formation. ${ }^{62-64}$ This effect was particularly underlined on silicon at the

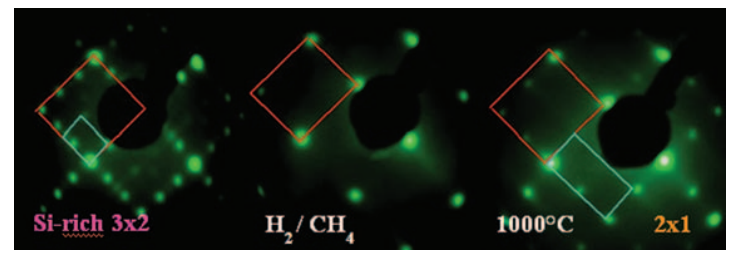

Figure 10.4 LEED patterns of $(3 \times 2) \mathrm{Si}$ rich $3 \mathrm{C}-\mathrm{SiC}$; after $\mathrm{H}_{2} / \mathrm{CH}_{4}$ plasma; and after annealing: $(2 \times 1)$ Si-terminated. ${ }^{54}$ 


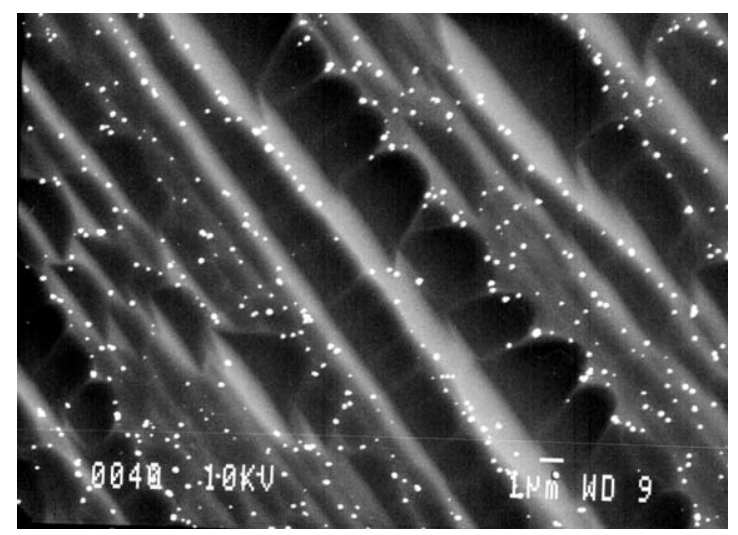

Figure 10.5 SEM picture of diamond crystals along steps in a silicon dimple. ${ }^{71}$

apexes of pyramids, ${ }^{65}$ sharp edges, ${ }^{66}$ whiskers ${ }^{67}$ and the edges of terraces on cleaved silicon. ${ }^{68}$ Several explanations have been attempted to justify the preferential nucleation on these sites, such as the minimization of the interfacial energy, ${ }^{66}$ the presence of more dangling bonds enhancing the chemisorption energy and the faster carbon saturation on these sites. ${ }^{69}$ In the presence of line defects on silicon (i.e., dislocations) the nucleation density was enhanced. ${ }^{70}$ The nucleation reached completion after a relatively short period of time and the nucleation rate could be modeled according to a Dirac delta function. Indeed, nucleation sites were available at the Si surface at the beginning of CVD.

Another approach consisted of transforming reconstructed vicinal surfaces into a silicon dimple by ultra-high vacuum (UHV) annealing. SEM investiontions (Figure 10.5) revealed a preferential location of diamond nucle 2 the vicinity of step edge 2 he link between structural defects and diamond nucleation was also established on a tungsten carbide (WC) substrat $P$ is study showed a correlation between broadening of the substrate $\mathrm{X}$-ray urriraction (XRD) peaks and the nucleation density $N_{\mathrm{d}}$, i.e., the number of diamond crystals per $\mathrm{cm}^{2}$ (Figure 10.6). Nucleation after etching of the WC-strained material leads to lower $N_{\mathrm{d}}$ values (by two orders of magnitude). The higher the full-width at half-maximum (FWHM) of the XRD peaks, the larger the nucleation density.

\subsubsection{Different Approaches for Enhanced Diamond Nucleation}

Several reports have reviewed in detail the different ex situ techniques developed to promote diamond nucleation. ${ }^{4,5}$ Two main objectives are important: (i) first, the enhancement of the nucleation density $N_{\mathrm{d}}$ (up to $10^{11}$ diamond crystals per $\mathrm{cm}^{2}$ ) on substrates as large as possible; (ii) second, heteroepitaxial diamond nucleation. Let us briefly summarize the methods 


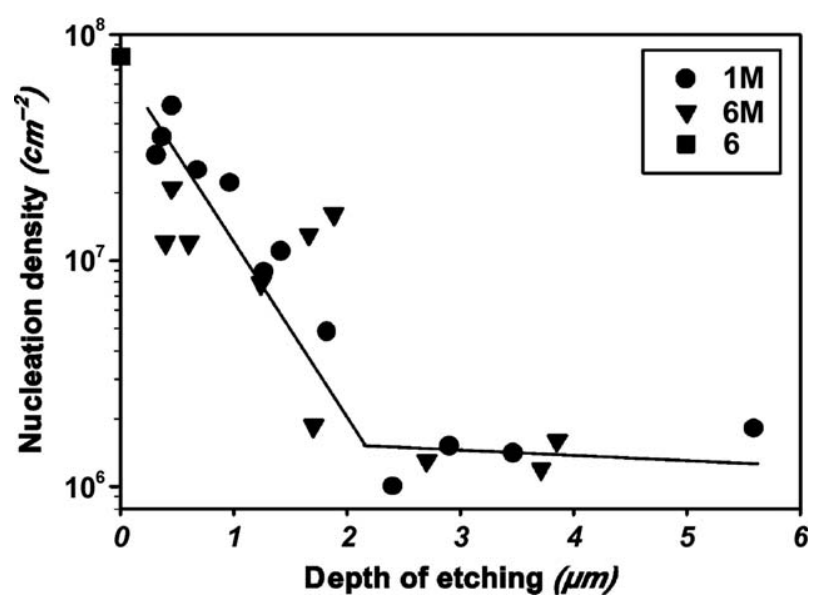

Figure 10.6 Evolution of the nucleation density versus etched depth of WC substrate. $^{72}$

used to obtain very high $N_{\mathrm{d}}$ (section 10.2.4.1). Then, the bias enhanced nucleation process (BEN), which permits us to reach both objectives, will be discussed (section 10.2.4.2). As an alternative to nucleation methods, seeding techniques, which directly provide diamond seeds at the surface, will be further described (section 10.3).

\subsubsection{Techniques for Diamond Nucleation Enhancement}

Very low nucleation densities $\left(N_{\mathrm{d}}=10^{3}-10^{5} \mathrm{~cm}^{-2}\right)$ are obtained on non-treated substrates due to the high surface energy of diamond relative to heterosubstrates, the low sticking coefficient of gaseous precursors and the competition of non-diamond phases. ${ }^{4,73}$

The first widely used method to enhance diamond nucleation was mechanical scratching of the substrates with abrasives ( $\mathrm{BN}, \mathrm{SiC}, \mathrm{Al}_{2} \mathrm{O}_{3}$, etc.). ${ }^{74,75}$ A better efficiency, with $N_{\mathrm{d}}$ values up to $10^{10} \mathrm{~cm}^{-2}$, was observed using diamond powder for scratching. An alternative method used an ultrasonic treatment with abrasive particles suspended in methanol or acetone. $^{76,77}$ Three different mechanisms for nucleation enhancement were proposed: ${ }^{78}$ (i) the mechanical treatment generated surface defects (edges, steps, dislocations) with lowered interfacial energy. It created available dangling bonds and a faster carbon saturation could happen at these defects; this effect was previously discussed (section 10.2.3). (ii) A seeding effect was also considered to occur, especially using diamond, c-BN or SiC powders. (iii) Finally, the production of non-volatile graphitic species was suggested, which could act as precursors for nucleation. ${ }^{42}$ A surface study on scratched Si (100) by X-ray photoelectron spectroscopy (XPS), Auger electron spectroscopy (AES) and SEN 2 monstrated well the coexistence of two pathways: a seeding pathway occurring by direct growth from part of the 
diamond seeds left by the mechanical pretreatment, and a nucleation pathway taking place through a stepwise process, including the formation of nucleation sites suitable for diamond nuclei. ${ }^{79}$ These aspects will be further described in the section on seeding techniques (section 10.3). Chemical etching or passivation surface treatments were also reported to create etch pits or to remove the surface oxide on silicon. ${ }^{80,81}$ Moderate $N_{d}$ enhancements were obtained using surface coatings ${ }^{82}$ or ion implantation $\left(\mathrm{Si}^{+}, \mathrm{C}^{+}\right) .{ }^{4,83}$

\subsubsection{Bias Enhanced Nucleation}

10.2.4.2.1 Principle. Compared to previous surface treatments, bias enhanced nucleation (BEN) is an in situ pretreatment, which consists of applying a DC bias voltage to the substrate with respect to the grounded reactor walls or to a second internal electrode. thechnique was first used for diamond nucleation by Yugo et al. ${ }^{84,8}$ an MPCVD reactor. A significant enhancement $\left(N_{\mathrm{d}}\right.$ values up to $10^{10}$ per $\left.\mathrm{cm}^{2}\right)$ was reported. Then, BEN was developed in different reactor geometries for microwave $^{86,87}$ or hot filament ${ }^{88-90}$ CVD techniques, applying DC and AC voltages, ${ }^{91}$ or pulse bias. ${ }^{92}$ Negative and positive bias voltages led to nucleation enhancement. ${ }^{93,94}$ Nevertheless, negative biasing is currently the most used technique. Under particular BEN conditions, heteroepitaxial nucleation was achieved on $\mathrm{Si}^{95}{ }^{9 \mathrm{C}-\mathrm{SiC}^{96}}$ and Ir surfaces. ${ }^{97}$

10.2.4.2.2 Relevant Parameters. The $\mathrm{CH}_{4} / \mathrm{H}_{2}$ MPCVD plasma is basically composed of $\mathrm{C}_{x} \mathrm{H}_{y}$ species in their neutral, radical and ionic forms. The $\mathrm{CH}_{4} / \mathrm{H}_{2}$ plasma chemistry was recently investigated in detail. ${ }^{98}$ Under BEN, a negative polarization is applied in most cases, leading to the formation of a cathodic sheath above the substrate. ${ }^{99}$ This induces two main phenomena: electron emission from the surface to the plasma, and surface bombardment by $\mathrm{H}_{y}{ }^{+}$and $\mathrm{C}_{x} \mathrm{H}_{y}{ }^{+}$ions. At first glance, the applied bias voltage and the duration seem to be pertinent parameters for BEN. Frequently used bias voltages are included between $\neg 100 \mathrm{~V}$ and $\neg 300 \mathrm{~V}$. However, due to the diverse reactor geometries, the bias voltage value by itself is quite meaningless. Indeed, the energy provided by the bias voltage is not totally transferred to the positively charged species as reported in the literature. ${ }^{100,101}$ On the other hand, the kinetic energy of accelerated $\mathrm{H}_{y}{ }^{+}$and $\mathrm{C}_{x} \mathrm{H}_{y}{ }^{+}$ions is a critical parameter. In situ, real-time, mass-selective energy analysis of the incoming ions has been carried out during BEN by Kátai et al. ${ }^{100}$ For example, the ion energy distributions were measured for a bias voltage of $\neg 200 \mathrm{~V}$ and a methane content of $4 \%$. All the involved species $\left(\mathrm{H}_{y}{ }^{+}, \mathrm{C}_{x} \mathrm{H}_{y}{ }^{+}\right)$have kinetic energies lower than $100 \mathrm{eV}{ }^{101}$ The second pertinent parameter to consider is the ion flux, which bombards the surface. According to Kátai et $a l^{100}$ it is closely related to the bias voltage and the methane content (Figure 10.7). 

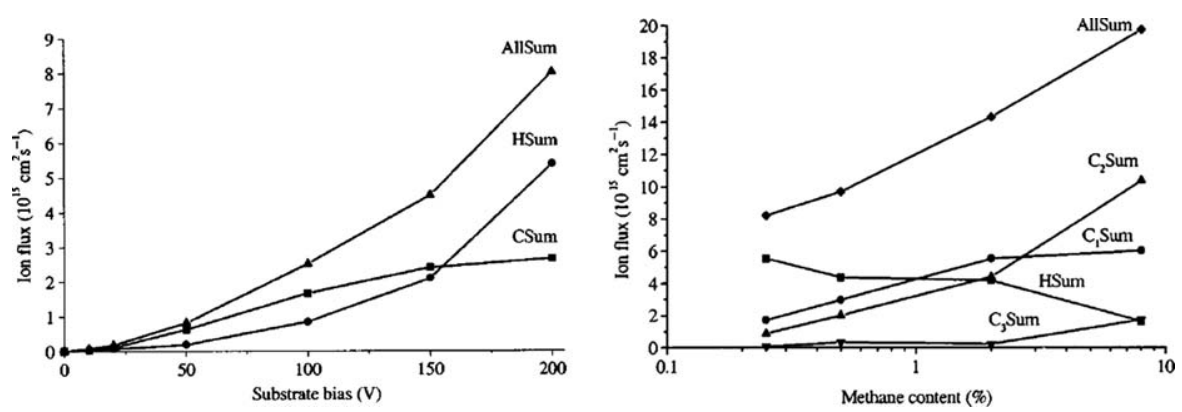

Figure 10.7 Left: Evolution of ion fluxes versus bias voltage; right: evolution of ion flux versus methane content. ${ }^{100}$

Moreover, the abundance of $\mathrm{C}_{x} \mathrm{H}_{y}{ }^{+}$ions is strongly dependent on the methane content. $\mathrm{C}_{2} \mathrm{H}_{y}{ }^{+}$ions become the major ion species for methane contents higher than $3 \%$ (Figure 10.7). This explains why higher methane contents $(2-10 \%)$ are commonly used for BEN compared to CVD growth. The importance of ion flux explains the very different BEN durations used in the literature. On silicon, Barrat et al. used ultra-short BEN steps of 10-90 s, ${ }^{102-104}$ while BEN procedures up to 15 min have been reported. ${ }^{105}$ On iridium, longer BEN steps from $60 \mathrm{~min}$ up to $180 \mathrm{~min}^{58,106,107}$ were applied using MPCVD plasma, whereas durations lower than $60 \mathrm{~s}$ were used with DC plasma. ${ }^{108}$ In this latter case, stronger ion bombardment is expected. In conclusion, concentrations, kinetic energies and the flux of ionic species impinging the substrate during BEN are the most relevant parameters. Unfortunately, very little experimental data is available in the literature.

10.2.4.2.3 BEN-induced Mechanisms. Surface modifications induced by MPCVD plasma on different substrates ( $\mathrm{Si}, 3 \mathrm{C}-\mathrm{SiC}$, Ir, etc.) were previously discussed (section 10.2.3). We underlined that the substrate's intrinsic reactivity plays an important role in diamond nucleation pathways. During $\mathrm{BEN}$, the induced mechanisms are also substrate dependent. ${ }^{109}$ Different competing phenomena have been observed (Figure 10.8).

The ion bombardment induced under BEN conditions led to subplantation of carbon species. This mechanism, first proposed by Gerber et al. ${ }^{110}$ was investigated in detail on silicon by Lifshitz et al. ${ }^{111}$ According to calculations, ${ }^{112}$ a minimum kinetic energy of $30 \mathrm{eV}$ is required for carbon ions to lead to subplantation into the silicon substrate. Experimental kinetic energy distributions ${ }^{100}$ confirmed that a significant part of $\mathrm{C}_{x} \mathrm{H}_{y}{ }^{+}$ions exhibit higher kinetic energy.

Surface bombardment can also lead to an enhanced diffusion of carbon species at the surface. Indeed, impinging ions transfer their kinetic energy to surface atoms. This mechanism was well identified on silicon by Jiang et al. ${ }^{113}$ who demonstrated that the spatial distribution of diamond islands generated by BEN was not random. A depletion zone was evidenced around existing diamond crystals, which is bias-voltage dependent. The two 


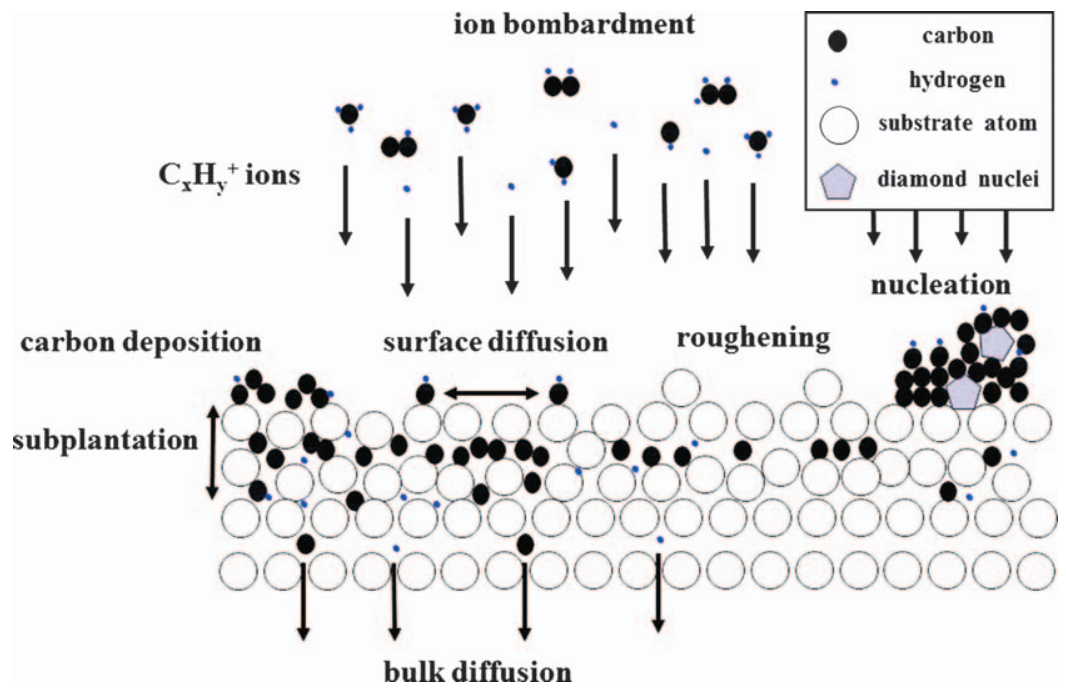

Figure 10.8 Different mechanisms reported or expected under bias enhanced nucleation.

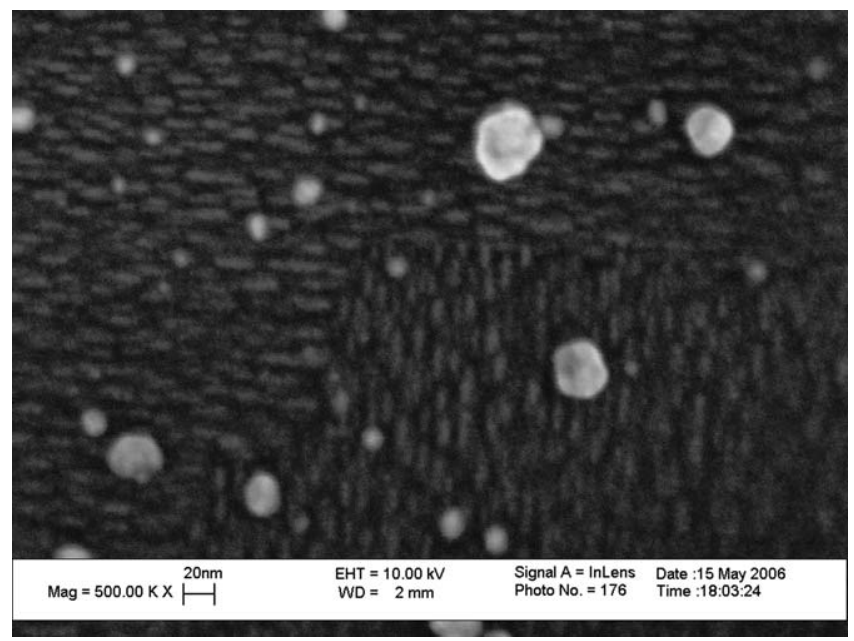

Figure 10.9 Surface roughening observed after BEN on 3C-SiC (001). ${ }^{116}$

previous mechanisms yield a higher carbon supersaturation at the surface, which is a required condition for diamond nucleation. The formation of diamond crystals under BEN then increases the electronic emission towards the plasma leading to a stronger sheath. ${ }^{114}$

Another consequence of ion bombardment is the surface roughening. Under proper BEN conditions, organized nanostructures could be formed at the surface. Perpendicular stripes corresponding to differer $\_$mains were observed after BEN on 3C-SiC surfaces ${ }^{115,116}$ (Figure 10.9). A surface 
roughening was also reported on iridium surfaces. ${ }^{58,117}$ It leads to the formation of furrows along $\langle 110\rangle$ directions, which may have an important role in the unique nucleation pathway on iridium. ${ }^{58,59}$ These surface nanostructures generated during BEN may significantly influence diamond nucleation, modifying the surface diffusion of species.

10.2.4.2.4 Heteroepitaxy. Bias enhanced nucleation treatments have revealed a powerful process to obtain diamond heteroepitaxial nucleation. In this case diamond crystals showed a crystallographic relationship with the substrate lattice. This property was achieved using a narrow window of BEN parameters. Among the wide variety of heterosubstrates, several are of interest for the growth of highly oriented diamond films (Table 10.1). The ideal heterosubstrate should have the lowest misfit parameter, a crystalline structure and a thermal expansion coefficient close to those of diamond, a high melting temperature and a weak reactivity under CVD. Among suitable substrates, c-BN exhibits the lowest misfit parameter and a weak difference of thermal expansion coefficient with diamond. Some studies reported epitaxial diamond crystals on (111) boron-terminated faces and (001) faces. ${ }^{118}$ Nevertheless, the availability of c-BN substrates remains low.

AQ:3 On (001) silicon, polar misorientations ${ }^{\ddagger}$ close to $5^{\circ}$ were obtained for diamond films of several tens of microns thick. ${ }^{43}$ The diamond crystalline quality is strongly limited by the formation of a silicon carbide interlayer under CVD (section 10.2.3). A significant improvement was observed using directly 3C-SiC (001) layers epitaxied on silicon substrates, yielding diamond films with a polar misorientation of $0.6^{\circ} .96$ This improved result is related to the weak reactivity of $3 \mathrm{C}-\mathrm{SiC}$ under CVD plasma (section 10.2.3). At the present time, the best (001) diamond films have b grown on iridium with polar and azimuthal misorientations of $0.34^{\circ} 0.16^{\circ}$, respectively. ${ }^{119}$

Table 10.1 Comparison of substrate properties for diamond heteroepitaxy.

\begin{tabular}{llllll}
\hline & $\begin{array}{l}\text { Crystalline } \\
\text { structure }\end{array}$ & $\begin{array}{l}\text { Misfit } \\
\text { parameter } \\
(\%)\end{array}$ & $\begin{array}{l}\text { Melting } \\
\text { temperature } \\
\left({ }^{\circ} \mathrm{C}\right)\end{array}$ & $\begin{array}{l}\text { Therm } \\
\text { coeffid } \\
\left(10^{-6} ;{ }^{\circ} C^{-1}\right)\end{array}$ & $\begin{array}{l}\text { Reactivity } \\
\text { under CVD }\end{array}$ \\
\hline $\begin{array}{l}\text { Diamond } \\
\text { Silicon }\end{array}$ & $F d 3 m$ & - & 3550 & 1.5 & $\begin{array}{l}\text { Weak } \\
\text { Carbide formation } \\
\text { etching }\end{array}$ \\
3C-SiC & $F 43 m$ & 52.0 & 1410 & 2.6 & $\begin{array}{l}\text { Surface roughening } \\
\text { Carbon dissolution }\end{array}$ \\
Platinum & Fm3m & 22.0 & 2830 & 4.6 & Weak \\
c-BN & $F 43 m$ & 10.0 & 1770 & 8.8 & Surface roughening \\
Iridium & $F m 3 m$ & 7.6 & 2727 & 0.6 & \\
\hline
\end{tabular}

${ }^{\ddagger}$ For (001) heteroepitaxy, the polar misorientation (or tilt) corresponds to the angular difference between the [001] direction of diamond lattice and the normal to the 1007 ) oriented substrate. The azimuthal misorientation (or twist) is defined as the angular iffrence between $\langle 100\rangle$ directions of diamond lattice versus the $\langle 100\rangle$ directions of the surface prane. 
For iridium, a unique nucleation pathway is occurring. While on other heterosubstrates, diamond crystals are formed via a 3D Volmer-Weber growth pathway, a pseudo-2D growth takes place on iridium in specific areas called domains. ${ }^{58,120,121}$ Within domains, a very high ratio of oriented diamond crystals ( $>90 \%$ ) is observed. A recent SEM/atomic force microscopy (AFM) combined study suggested that furrows created by iridium roughening could be involved in domain formation. ${ }^{59}$ For (111) heteroepitaxy, Tachibana et al. achieved the growth of diamond films on platinum with a polar misorientation close to $1^{\circ}$ using either BEN or a seeding/annealing treatment. ${ }^{51}$

\subsection{Nanodiamond Seeding}

Among the methods developed over the last decades to promote the growth of ultrathin diamond layers, a so-called "seeding" technique appeared as the more versatile approach to enable diamond coating on heterosubstrates. It relies on the deposition of diamond nanoparticles (nanodiamonds, NDs) on a substrate, which act as seeds for diamond growth. Unlike the BEN technique previously described (section 10.2.4), seeding is not truly a nucleation technique as growth starts from already deposited nanometric diamond phases, even if the confusion is often encountered in the literature. However, this technique enables diamond growth on a large variety of substrates as no electrical conductivity is required. Moreover, it is theoretically not limited by the shape or the dimension of the substrate. Indeed, in the case of diamond growth initiated by nanodiamond seeds, the main limitations come from the CVD process, hardly achievable on substrate larger than six inches.

\subsubsection{Abrasion Techniques Involving Particles}

Development in the 90s of nanodiamond seeding toward CVD growth partly resulted from the evolution of abrasion methods, originally developed in 80 s to enhance the nucleation density on a substrate. ${ }^{122-125}$ These abrasion techniques rely on the formation of defects on the substrate by the mean number of diamond or non-diamond particles applied on the substrate by mechanical strength (polishing or scratching) or by ultrasonic agitation. ${ }^{125}$ Typically, a nucleation density $N_{\mathrm{d}}$ of $10^{7}-10^{8} \mathrm{~cm}^{-2}$ is routinely obtained on a scratched silicon substrate, which compares to $10^{4} \mathrm{~cm}^{-2}$ on non-scratched substrates. ${ }^{126}$ In this approach the enhancement of $N_{\mathrm{d}}$ is expected to be linked to the minimization of interfacial energy on sharp convex surfaces, the breaking of a number of surface bonds and pid carbon saturation (fast carbide formation) at sharp edges. ${ }^{125}$ Different abrasive materials have been studied and ranked, such as oxides, silicides, carbides and nitrides. For instance, aluminum oxides or cubic boron nitrides were shown to be much more efficient at reaching a high nucleation density than silicon or zinc oxides. ${ }^{42}$ However, if diamond particles are used, an even higher nucleation density is generally measured as the embedding 
of small residual diamonds in the surface contributes to the nucleation enhancement through the growth occurring on these diamond seeds. ${ }^{77,127,128}$ In ultrasonic treatments with diamond particles the predominant nucleation mechanism has even been shown to be mainly related to seeding by "diamond dust" on the substrate surface. ${ }^{76}$ Consequently, in order to maximize this effect, the use of diamond particle slurries became rapidly predominant instead of non-diamond particles. ${ }^{129,130}$ In parallel, the particle diameter used in the diamond slurries reduced, ${ }^{77}$ but significant differences between both abrasion methods (mechanical polishing and ultrasonic treatment) appeared. For mechanical abrasion, the use of smaller diamond particles rapidly appeared as more efficient in enhancing the nucleation density by the combined effect of finer defects and more embedded seeds. ${ }^{124,130,131}$ In contrast, the use of smaller particles, with nanometric diameters and dispersed in slurries for ultrasonic agitation, did not directly enhance the nucleation density on the substrate. Several authors emphasize that the smallest particles have insufficient momentum to induce damage on the substrate or embedding. ${ }^{77,132,133}$ To increase this momentum, the use of larger particles in the ND slurries has been shown to be efficient, a socalled "hammering" effect. Note that these larger particles can be made of diamond or non-diamond materials, as reported by Akhvlediani et al. ${ }^{132}$ with the use of micrometric diamond, alumina and titanium particles. If these abrasion/seeding mixed methods are still in use to produce thick diamond layers, they are limited by the damage induced on the substrate and the high probability of leaving large particles on the substrate. These drawbacks drastically impact the diamond quality of the grown layer and are incompatible with the quality standards required for MEMS processing, and optical or tribological devices.

\subsubsection{Controlled Deposition of Nanodiamonds on Substrates}

The progressive availability on the market of much smaller diamond particles enabled the development of methods only devoted to the deposition of diamond crystals on a substrate without the formation of defects. The main advantage concerns the possibility to not damage the substrate, an essential requirement in some applications (notably, optics and sensing), and the possibility to deposit a homogenous size distribution of diamond seeds on the substrate. The quality of the resulting diamond film is thus directly dependent on the quality of the seeding. Three major parameters drive the characteristics of the grown layer: (i) the density of seeds $N_{\mathrm{s}}$ deposited on the substrate; (ii) the spatial homogeneity of the deposit; and (iii) the size distribution of the particles deposited on the substrate. The former will mainly impact the thickness of the resulting coalesced layer, while the two others factors drive the homogeneity and the roughness of the grown layer. Therefore, an efficient seeding process will rely on the quality of the 
deposition technique, but also on the quality of the nanoparticles suspension. Prior to the description of the major seeding methods reported so far in the literature, a short introduction on NDs suspensions will be given below.

\subsubsection{Nanodiamond Suspensions}

10.3.2.1.1 Nanodiamond Synthesis. The formation of clusters and the superficial chemistry of NDs are closely related and mainly depend on their origin. Among the different synthesis methods of NDs, detonation ${ }^{134}$ and milling proqano s $^{135}$ are maybe the most widely used. In the detonation metho 2 rticles are synthesized from carbon provided by the explosive itself. During a detonation and under a lack of oxygen, the conditions of temperature and pressure required for the formation of a diamond phase can be met for a short time, leading to the synthesis of nanodiamonds. ${ }^{136}$ The diameter is thus determined by the duration of the detonation wave, which gives rise to uniform primary particles generally around $5 \mathrm{~nm}$. However, non-diamond phases continue to be synthesized after the pressure drops, which generally cover the particles with $\mathrm{sp}^{2}$ or amorphous carbon species, which surround small clusters of a few nanodiamonds (Figure 10.10). Thorough purification steps are thus required to remove all these non-diamond phases and dedicated techniques to deagglomerate the clusters have been developed, such as bead milling ${ }^{137,138}$ or air oxidation. ${ }^{139}$ However, access to primary particles is still a challenge and detonation nanodiamonds usually carry on their surfaces a small amount of non-diamond phases.

Another approach to synthesize diamond nanoparticles consists in the milling of micrometric crystallites (natural or synthetic). ${ }^{135}$ The resulting nanodiamonds are less contaminated with non-diamond phases on their surface and are less sensitive to aggregation. Nevertheless, they exhibit a 
broader size distribution than detonation particles and diameters below 10 $\mathrm{nm}$ are not yet commercially available. Finally, as a major difference between both production routes, if detonation nanodiamonds are roughly spherical, nanodiamonds synthesized by a milling process exhibit the typical facets of a diamond crystallite, even at the nanometer scale.

10.3.2.1.2 Surface Charge. A key parameter for the colloidal stability of nanodiamonds is their surface potential $E_{\text {ZETA }}$ and the resulting electrostatic forces. If this surface charge is high enough in absolute value $\left(E_{\text {ZETA }}>|30| \mathrm{mV}\right)$, repulsive forces between the particles are able to ensure good colloidal stability. The diamond core is surrounded by a versatile carbon layer on which different chemistries can be found. The use of oxidative treatments during the purification steps gives rise to an oxidized surface, mainly composed of carboxylic, alcoholic or etheric groups. ${ }^{141}$ Polar groups ensure a hydrophilic surface, but also may confer a charge to the particle, which will depend on the $\mathrm{pH}$. For instance, carboxylic groups can be found on nanodiamonds exposed to a strong oxidative treatment (air annealing or an acid treatment). Above $\mathrm{pH} 4$, the carboxylate form prevails, leading to a negative zeta potential, generally below $\neg 40 \mathrm{mV}$ if well dispersed. This method is commonly used to prepare stable colloidal suspension of nanodiamonds. Conferring a positive charge to nanodiamonds is more tedious. Surface functionalization can be performed to cover the particle with cationic groups (e.g., ammonium groups). However, it has been recently reported in the literature that "unfunctionalized" particles (e.g., without noticeable acid/base groups) can exhibit such positive zeta potentials, especially after a reduction treatment under hydrogen or a vacuum annealing. ${ }^{142,143} \mathrm{~A}$ recent hypothesis on the origin of this positive charge involves adsorption of oxygen on the surface of the particles, allowing hole doping at the surface of the nanodiamonds. ${ }^{142}$

10.3.2.1.3 Solvent. The choice of solvent is also a major factor when assessing the colloidal stability of nanodiamonds. Ultrapure water is so far the wildest solvent used to suspend nanodiamonds, but alternatives are beginning to be reported. For instance, the Shenderova group has published several studies on nanodiamonds dispersed in dimethylsulfoxide (DMSO). ${ }^{144}$ They showed that positively charged nanodiamonds dispersed in DMSO often lead to more stable suspensions than when dispersed in water. On the other hand, suspensions in DMSO of negatively charged nanodiamonds are hard to realize. These researchers also succeeded in achieving stable suspensions in mixtures of DMSO combined with a second solvent, such as alcohol, acetone or water. This aspect is of great importance for nanodiamond seeding, as alcohols, for instance, possess a low surface tension and a low temperature of vaporization.

(D) summarize, nanodiamonds can differ in many aspects, such as: (i) spherical or faceted shape; (ii) surrounded or not with non-diamond carbon species; (iii) scattered surface chemistry; (iv) surface charge; (v) sizes from a 
few nanometers to tens of nanometers; and (vi) polydispersed (or not) distributions. This diversity will directly impact the characteristics of the colloidal suspension of nanodiamonds and, consequently, the seeding method. As will be described, the dispersion method is mainly chosen according to these characteristics: the sign of the zeta potential (which depends on the surface chemistry and the solvent), the tendency of the suspension to agglomerate (depends on detonation or milling synthesis) or the polydispersity of the suspension.

\subsubsection{Stability of the Nanodiamonds Under CVD Plasma}

The aim of nanodiamond seeding is the growth promotion of CVD diamond layers. However, the chemical or thermal stability of $5 \mathrm{~nm}$ diamond cores under CVD plasma conditions is not obvious, as well as the interaction between the seeds and the substrate under harsh conditions. Arnault et al. reported on a detailed XPS analysis of detonation particles seeded on a silicon substrate under pure hydrogen MPCVD plasma. ${ }^{145}$ They revealed that $\mathrm{sp}^{2}$ species are entirely etched by atomic hydrogen, without altering the $\mathrm{sp}^{3}$ seeds even after a high temperature treatment $(T=1213 \mathrm{~K})$. At the same time, the formation of silicon carbide at the interface between the seed and the silicon substrate has been identified, more predominant at $1213 \mathrm{~K}$ than at $993 \mathrm{~K}$ (Figure 10.11). This interlayer has been predicte $D$ us to significantly enhance the adhesion of nanodiamonds on the surstrate and consequently the adhesion of the grown diamond layer. Indeed, beyond the roughness of the substrate known to enhance the adhesion of the diamond layer, specific studies also reported the impact of such interlayers on the adhesion $^{146,147}$ or, conversely, on the possibility to realize spontaneously detaching self-standing diamond films. ${ }^{148}$ The stability of the nanodiamonds under CVD plasma was also confirmed by Sumant et al., ${ }^{149}$ who studied the underside of a diamond nanocrystalline film grown from detonation nanodiamonds. Surface analysis showed that $98 \%$ of the underside was composed of diamond, the rest being mainly composed of $\mathrm{sp}^{2}$ carbon attributed to the detonation nanodiamonds used for the seeding.

\subsubsection{Methods for Seeding}

10.3.2.3.1 Evaporation of Nanodiamond Suspensions. The easiest way to transfer and deposit nanodiamonds from a colloid onto a surface obviously consist in the deposition of a drop of nanodiamond suspension, the solvent being evaporated naturally. Unfortunately, such a deposit generally leads to a poor spatial homogeneity due to convection forces during the drying process, combined with a progressive aggregation of the nanodiamonds during the concentration increase. Shenderova et al. ${ }^{144}$ illustrated this last point by allowing nanodiamond suspensions to dry and be reconstituted in different solvent. They revealed that a dried aqueous suspension that was reconstituted in water promoted a strong 

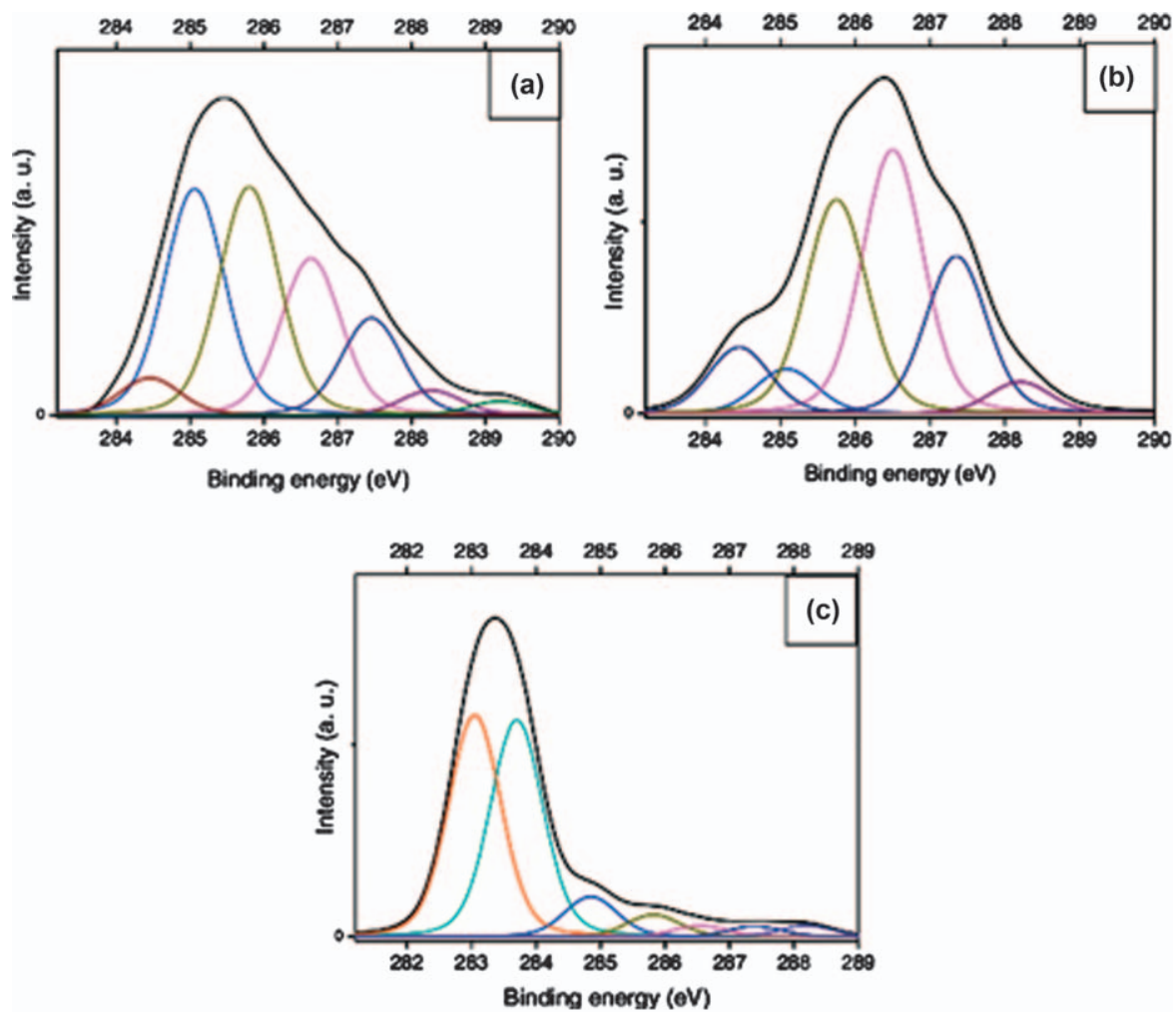

Figure 10.11 XPS C1s core level sp (ct); a) initial state, after a UHV treatment; b) at $1073 \mathrm{~K}$; c) at $117 \% 45$

agglomeration of the NDs (Figure 10.12). To underline the effect of the solvent, a similar experiment, performed from a DMSO suspension, which was dried and the resulting particles reconstituted in water, maintains the initial average diameters of the nanodiamonds.

To overcome these issues, different strategies to spread and dry nanodiamond suspensions homogeneously on a substrate have been explored in the literature. One of the most efficient is the use of a spin coater to ensure a good dispersion of NDs on a flat substrate and enhance the drying step. The technique consists of the deposition of a volume of ND suspension on the substrate, which is then spin-coated at a defined rotation speed. This basic approach can be used either with nanodiamonds suspended in water or alcohol, ${ }^{150,151}$ or with composite suspensions, in which organics can be added to modulate some parameters, such as the viscosity. For instance, the addition of polyvinyl alcohol (PVA), a water-soluble polymer, in a waterbased suspension of nanodiamonds was shown to be highly efficient in realizing dense seeding. PVA is expected to help the formation of a homogenous polymeric layer on the substrate as it exerts a stabilizing effect on the nanodiamonds. ${ }^{152,153}$ Scorsone et al. reported the use of such composite 
Sizes of ND in initial suspensions as well as after drying and re-dispersion.

\begin{tabular}{llll}
\hline Initial solvent & ND size in initial solvent, $\mathrm{nm}$ & ND size after drying and resuspension, nm & Solvent for resuspension \\
\hline DMSO & 35 & 35 & DMSO \\
DMSO & 35 & 37 & $\mathrm{H}_{2} \mathrm{O}$ \\
DMSO & 35 & 50 & DMSO:methanol $^{\mathrm{a}}(1: 9)$ \\
$\mathrm{H}_{2} \mathrm{O}$ & 30 & 98 & $\mathrm{H}_{2} \mathrm{O}$ \\
$\mathrm{DMSO}^{\mathrm{H}} \mathrm{H}_{2} \mathrm{O}^{\mathrm{b}}(1: 9)$ & 40 & 55 (res.) & $\mathrm{H}_{2}^{\mathrm{O}}$ \\
$\mathrm{H}_{2} \mathrm{O}+\mathrm{DMSO}^{\mathrm{d}}(1: 1)$ & 30 & 48 (res.) & $\mathrm{H}_{2}^{\mathrm{O}}$ \\
\hline
\end{tabular}

a ND powder was first dispersed in DMSO, then methanol added.

b $\mathrm{ND}$ was fractionated in a mixture DMSO $/ \mathrm{H}_{2} \mathrm{O}$.

c res. - Small residue presents.

d ND was fractionated in water, then DMSO added.

Figure 10.12 Sizes of NDs in their initial suspensions, as well as after drying and re-dispersion in different solvents. ${ }^{144}$ 

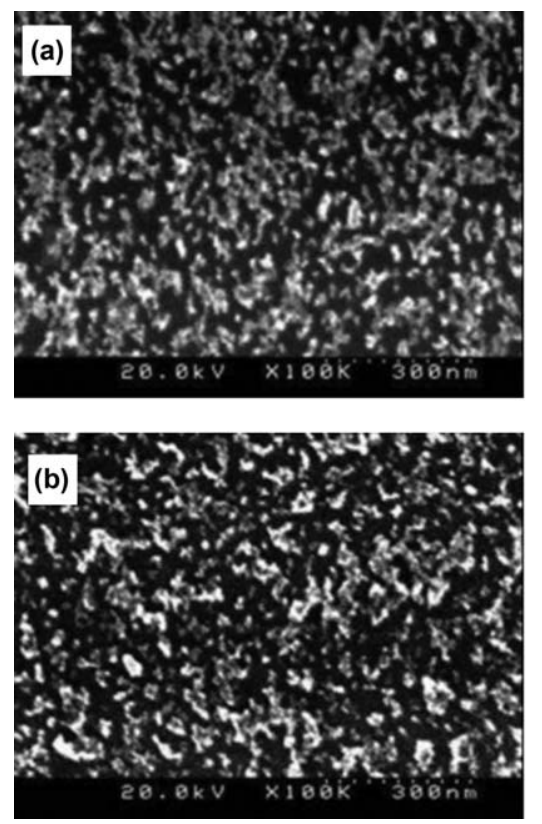

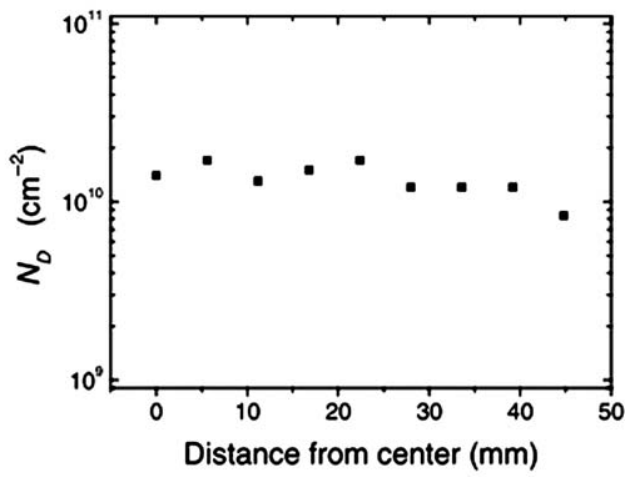

Figure 10.13 (Left) SEM images of seeded silicon substrate prepared from a $0.1 \%$ wt/wt nanoparticle with $1.5 \%$ wt/wt PVA aqueous solution after (a) pyrolysis under hydrogen plasma and (b) pyrolysis in air at $350{ }^{\circ} \mathrm{C}$. (Right) Density of seeds across the radius of a 4 inch silicon wafer. ${ }^{33}$

mixtures (PVA/nanodiamonds) to finely control the density of seeds deposited on a substrate by manipulating the nanodiamond concentration. ${ }^{152}$ High density seed layers $\left(N_{\mathrm{s}}>10^{10}\right.$ seeds $\left.\mathrm{cm}^{-2}\right)$ were deposited over 4-inch substrates (Figure 10.13), matching the required characteristics to grow ultrathin diamond layers. In this study a thorough XPS study was also conducted to exclude any effect of the polymer on the diamond growth, showing that the polymer matrix in which the nanodiamonds are embedded instantly burns away under the plasma conditions at the beginning of the growth. Such methods involving spin-coating of nanodiamond suspensions give rise to excellent results on flat surfaces, but may encounter limitations on $3 \mathrm{D}$ shapes due to screening effects.

10.3.2.3.2 Seeding by Adhesion Transfer. An alternative to solvent evaporation to spread nanodiamonds on a substrate consists of the exploitation of specific interactions between both surfaces (substrate and nanodiamonds). As detailed above, nanodiamonds carry on their surface a complex chemistry, which yield adequate surface properties for adhesion. Among them, electrostatic forces can be used to promote the self-adhesion of nanoparticles onto an oppositely charged substrate. For instance, silicon, which is the most common substrate on which polycrystalline diamond is grown, exhibits a negative surface charge due to the native 
oxide layer (thus also including silica-based substrates, like quartz, glass, annealed silicon, etc.). In this case electrostatic adhesion will require positively charged nanod @inds, which can be found either commercially or prepared by different ammealing methods (see section 10.3.2.1). Note that such an approach based on electrostatic interactions requires careful handling of the nanodiamond suspension, especially regarding the $\mathrm{pH}$ and the solvent chosen.

To achieve electrostatic seeding, the easiest method consists of dipping the silicon substrate in a positively charged nanodiamond slurry under ultrasonic agitation. ${ }^{143,149,154-157}$ Ultrasonic agitation is used here to maintain an optimized dispersion of the nanodiamonds, especially when detonation nanoparticles are used. Agitation also enhances the diffusion of the particles over the substrate to promote their self-adhesion and the seeding homogeneity. In this case the adhesion of the nanodiamonds is expected to be due to electrostatic forces and not to mechanical embedding of the seeds in the substrate, for which larger particles in the slurry are required to confer enough momentum to the nanodiamonds ("hammering", effect see section 10.3.1). This method, so-called "ultrasonic seeding", is not limited to pure aqueous suspensions of nanodiamonds. DMSO-based suspensions were also reported in the literature to work efficiently with this approach $^{144}$ (Figure 10.14). However, a small fraction of methanol had to be added to the DMSO slurries because of its high surface tension, high boiling point and slow evaporation. With this ultrasonic seeding approach based on electrostatic adhesion, highly dense seeding is achieved with $N_{\mathrm{s}}$ densities regularly reported above $10^{11}$ seeds $\mathrm{cm}^{-2} \cdot{ }^{154,156}$ Furthermore, as the adhesion of the first layer of nanodiamonds will largely screen the substrate charge, the formation of several layers of nanodiamonds is limited. Using highly dispersed detonation nanodiamonds (typically with diameters below $10 \mathrm{~nm}$ ), Williams et al. reported the growth of an ultrathin diamond coating
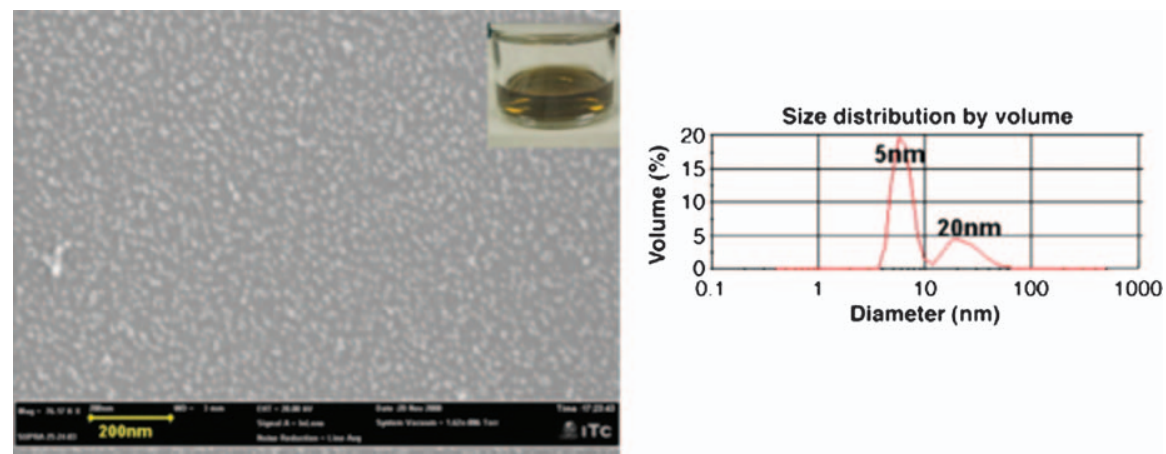

Figure 10.14 (Left) SEM image of NDs seeded on silicon using a mixture of $0.5 \%$ NDs in DMSO (1 part) and methanol (3 parts), and treated in an ultrasonic bath. The inset illustrates the ND/DMSO/MeOH seeding slurry. (Right) Particle size distribution. ${ }^{144}$ 
with a thickness below $70 \mathrm{~nm} .{ }^{154}$ Furthermore, this technique also allows the seeding of complex surfaces with 3D shapes. For instance, Si tips, carbon nanotubes $^{158}$ and polymeric stripes ${ }^{159}$ have been covered with nanodiamonds by ultrasonic seeding.

Despite the efficiency of this "ultrasonic seeding", which is driven by electrostatic forces, a limitation can come from the undesired charge of the substrate or of the nanodiamonds. For instance, carboxylated nanodiamonds exhibiting a negative zeta potential at neutral $\mathrm{pH}$ will not stick spontaneously on a silicon substrate, even with a highly dispersed suspension. A method to control and adapt the surface charge of the substrate is thus required. Polarization of the substrate to initiate an electrophoretic deposition is possible and has been explored by different authors. ${ }^{158,160,161}$ For instance, silicon field emission tips for cold cathode fabrication have been seeded by such an approach with nanodiamonds of different charge by adapting the applied voltage. Selective seeding on polarized gold strips was also demonstrated by Hens et al. ${ }^{158}$ using positively charged nanodiamonds functionalized with amino groups.

However, electrophoretic deposition implies a conductive substrate. To overcome this limitation, an efficient alternative resides in the use of polyelectrolytes to coat the substrate and confer to them the required charge. Polycationic polymers, such as poly(diallyldimethylammonium) chloride (PDDAC), will give a positive charge to the surface, while polyanionic polymers, such as poly(styrenesulfonate) (PSS), will confer a negative charge. These polymers, which are soluble in water, can be deposited as a very thin layer of a few nanometers on almost all materials, even with complex 3D features. By this way, insulating materials or patterned substrates exhibiting different charges can be coated and have a homogenous charge on their entire surface. The seeding will thus be achieved by a layer-by-layer approach, ${ }^{162,163}$ with the first layer of polyelectrolyte deposited on the substrate by dipping the substrate in a polyelectrolyte solution. After thorough rinsing, the second layer, made of nanodiamonds, is deposited, also by dipping the coated substrate in a nanodiamond suspension of opposite charge. ${ }^{164-168}$ A first monolayer of nanodiamonds is thus achieved, and multilayers of nanodiamonds can also be deposited on the substrate by repeating this sequence. Note that the use of this very thin polymer coating has no consequence on the diamond growth as all the polymer is immediately burned away by the plasma. The density reached by this technique is equivalent to those achieved by ultrasonic seeding $\left(10^{11}\right.$ seeds $\left.\mathrm{cm}^{-2}\right)$. As for the other techniques based on the electrostatic adhesion of seeds, 3D complex structures can also be seeded through this approach. Girard et $a .^{165}$ reported the fabrication of alldiamond nanostructures grown in nanoscaled silicon molds seeded by this method (Figure10.15).

10.3.2.3.3 Patterned Seeding. 3D micro- or nano-structures are often required in the design of diamond-based microelectromechanical systems 

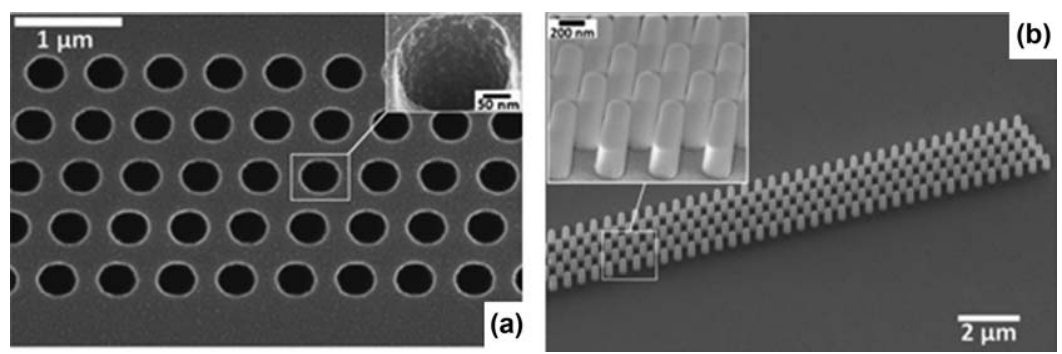

Figure 10.15 SEM pictures of (a) a mold made of silicon structured with wells $\left(200 \times 800 \mathrm{~nm}^{2}\right)$ after seeding; (b) diamond nanostructures grown in the molds after silicon dissolution. ${ }^{165}$

(MEMS) or nanoelectromechanical systems (NEMS), optical systems or biomedical devices. Depending on the targeted properties, all-diamond structures may have to be realized as a simple coating of nanocrystalline diamond (as described above) may not be sufficient. Top-down approaches can be considered, mostly based on the etching of a thick diamond layer through a mask. ${ }^{169,170}$ Almost perfect structures can be achieved with this approach for photonic applications, either in monocrystalline ${ }^{171}$ or polycrystalline diamond. ${ }^{172}$ However, etching of diamond is time consuming and post-processing can be cumbersome. An alternative bottom-up approach is also possible, based on the patterning of the seeds, to obtain a selective area deposition (SAD) of the diamond layer. However, a reliable selective growth will be achieved only if several orders of magnitude exist between voluntary seeded areas and the residual density of nucleation of the substrate. Here, two strategies have been reported in the literature. The first relies on the seeding of a substrate on which the selective removal of the nanodiamond has been performed. ${ }^{173}$ For instance, the patterning of the nanodiamonds can be achieved by a plasma etching of unwanted nanoparticles through the protection of an aluminum hard mask deposited by lithography. ${ }^{174}$ Babchenko et al. described a technique in which patterning of the seeds is obtained through the wet chemical removal of nanodiamonds with $\mathrm{a} \mathrm{SiO}_{2}$ layer on pre-defined areas by a buffer oxide etchant. ${ }^{175,176}$ Selective growth on patterned seeding can also be achieved by a selective deposition of the seeds. Fox et al. developed a technique based on water ink containing nanodiamonds. ${ }^{177}$ By standard ink jet technology, local seeding has been realized by Fox et al. on glass, silicon, copper and fused quartz (Figure 10.16) with micrometric patterns. An alternative at the nanometric scale has been recently proposed by Zhuang et al., who used microcontact printing with a nanodiamond-based ink. ${ }^{178}$ Using the electrostatic seeding method, a pre-patterning of the polyelectrolyte layer can also be used to drive the deposition of the nanodiamonds only on the regions of opposite charge. ${ }^{164,166}$ 

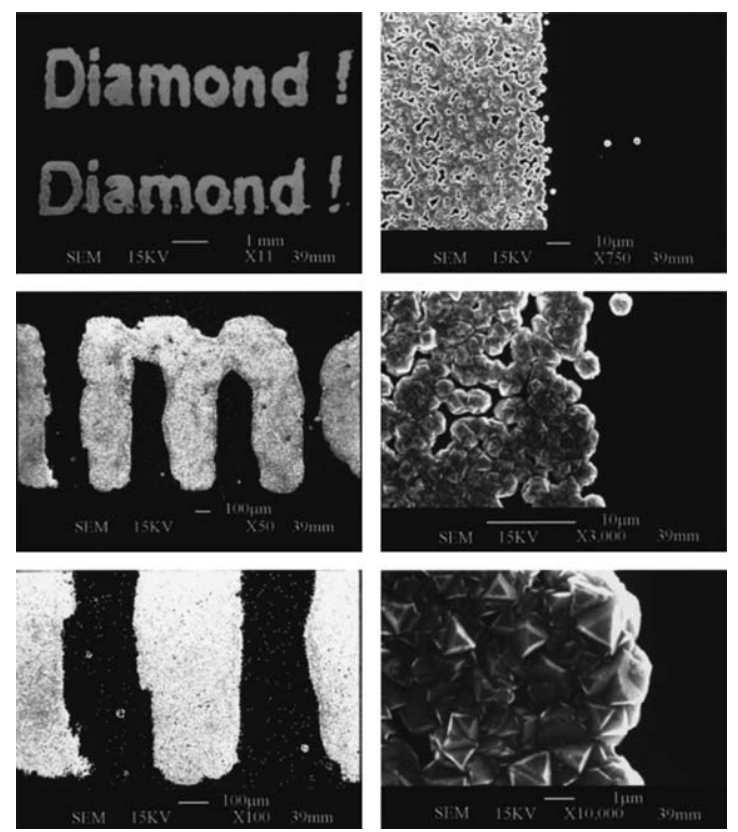

Figure 10.16 SEM pictures, at various magnifications, of ink-jet seeded CVDgrown diamond on a silicon substrate. ${ }^{177}$

\subsection{Conclusion}

The control of ultrathin diamond films $(<150 \mathrm{~nm})$ is a major challenge for applications (heat dissipation, NEMS and MEMS). The present chapter focuses on the two experimental approaches investigated in the literature: the nucleation and seeding pathways.

Firstly, we have shown that, for diamond, both homogeneous (i.e., nucleation in a gas phase) and heterogeneous (i.e., nucleation onto a surface) nucleation has been experimentally observed. Focusing on heterogeneous nucleation, we underlined that the intrinsic reactivity of a given heterosubstrate under CVD conditions is an essential parameter. It leads to different mechanisms competing with diamond nucleation and participates in the interface formation. We have also mentioned the role of structural defects on heterogeneous diamond nucleation. Then, we focused on the BEN process, which remains the most controllable in situ nucleation technique. The most relevant parameters (concentration, kinetic energy and the fluxes of ionic species) were detailed. A brief state of the art was given for heteroepitaxy comparing the promising substrates.

In the second part of this chapter we reviewed the seeding techniques, focusing on the controllable deposition of nanodiamonds on surfaces (evaporation, adhesion transfer, patterning). Describing the main characteristics of a nanodiamond suspension (particle shape, surface chemistry 
Table 10.2 Comparison of BEN and seeding.

\begin{tabular}{ll}
\hline Bias enhanced nucleation & Seeding \\
\hline Advantages & \\
- In situ technique & - Large substrates (up to six inches) \\
- Diamond heteroepitaxy & - 3D substrates \\
- Good film adhesion & - Variety of substrates \\
Drawbacks & - Film adhesion to be improved \\
- Non-conductive substrates & - Not usable for heteroepitaxy \\
- 3D substrates & \\
- Substrate size limited by CVD reactor & \\
$\quad$ geometry & \\
\hline
\end{tabular}

and charge, size distribution, solvent nature), we underlined the relevance of the colloidal chemistry on the seeding quality. The stability of the diamond nanoparticles under plasma conditions was also mentioned.

Both pathways (nucleation and seeding) were successfully applied to obtain diamond layers with thicknesses lower than $150 \mathrm{~nm}$. Nevertheless, each pathway possesses its own advantages and drawbacks (Table 10.2). Seeding is powerful for diamond deposition on large or non-conductive substrates, while BEN remains the best approach for heteroepitaxy and welladherent films. ${ }^{179}$

\section{References}

1. J. P. Mazellier, O. Faynot, S. Cristoloveanu, S. Deleonibus and P. Bergonzo, Diam. Relat. Mater., 2008, 17, 1248.

2. M. Lions, S. Saada, B. Bazin, M.-A. Pinault, F. Jomard, F. Andrieu, O. Faynot and P. Bergonzo, Diam. Relat. Mater., 2010, 19, 413.

3. W. Zhu, G. P. Kochanski and S. Jin, Science, 1998, 282, 1471.

4. H. Liu, D. S. Dandy, Diamond Chemical Vapor Deposition: Nucleation and

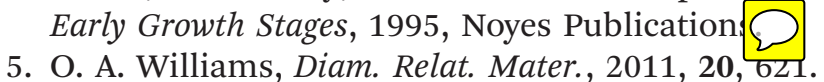

6. M. Volmer and A. Weber, Z. Physik Chem., 1926, 199, 277.

7. R. Kern, G. de Lay, J. J. Métois in Current Topics in Materials Science, ed. E. Kaldis, vol. 3, 1979, pp. 135-41

8. S. Barrat, Vide: Science, technique et plications, 2001, 2/4, 320.

9. B. V. Derjaguin and D. V. Fedoseev, Scientific American, 1975, 233, 102.

10. H. Fujimoto, Y. Kitagawa, H. Hao and K. Fukui, Bulletin of the Chemical Society of Japan, 1970, 43, 52.

11. S. A. Godleski, P. V. Schleyer, E. Osawa and W. T. Wipke, Prog. Phys. Org. Chem., 1981, 13, 63.

12. M. Frenklach and K. Spear, J. Mater. Res., 1988, 3, 133; G. A. Raiche and J. B. Jeffries, Carbon, 1990, 28, 796.

13. S. Mitura, J. Cryst. Growth, 1987, 80, 417. 
14. W. Howard, D. Huang, J. Yuan, M. Frenklach, K. E. Spear, R. Koba and A. W. Phelps, J. Appl. Phys., 1990, 68, 1247.

15. M. Frenklach, R. Kematick, D. Huang, W. Howard, K. E. Spear, A. W. Phelps and R. Koba, J. Appl. Phys., 1989, 66, 395.

16. K. Tsugawa, M. Ishihara, J. Kim, Y. Koga and M. Hasegawa, Phys. Rev. B, 2010, 82, 125460.

17. H. M. Jang and N. M. Hwang, J. Mater. Res., 1998, 13, 3527.

18. N. M. Hwang, J. Cryst. Growth, 1999, 198-199, 945.

19. L. M. Ghiringhelli, C. Valeriani, J. H. Los, E. J. Meijer, A. Fasolino and D. Frenkel, Molecular Physics, 2008, 106, 2011.

20. R. S. Lewis, T. Ming, J. F. Wacker, E. Anders and E. Steel, Nature, 1987, 326, 160.

21. A. P. Jones, L. B. d'Hendecourt, S.-Y. Sheu, H.-C. Chang, C.-L. Cheng and H. G. M. Hill, Astronomy \& Astrophys, 2004, 416, 235.

22. V. N. Mochalin, O. Shenderova, D. Ho and Y. Gogotsi, Nature Nanotech, 2012, 7, 11.

23. M. Tomellini and B. Bunsenges, Phys. Chem., 1995, 99, 838.

24. M. Fanfoni and M. Tomellini, J. Phys.: Condens. Matter, 2005, 17, R571.

25. A. N. Kolmogorov, Bull. Acad. Sci. URSS (cl. Sci. Math. Nat.), 1937, 3, 355.

26. W. A. Johnson and R. F. Mehl, Trans. Am. Inst. Min., Metall. Pet. Eng., 1939, 135, 416.

27. M. J. Avrami, Chem. Phys., 1939, 7, 1103.

28. M. J. Avrami, Chem. Phys., 1940, 8, 212.

29. M. Tomellini and M. Fanfoni, Int. J. Nano Science, 2010, 9, 1.

30. M. Tomellini and M. Fanfoni, Diam. Relat. Mater., 2010, 19, 1135.

31. R. Polini, M. Tomellini, M. Fanfoni and F. Le Normand, Surf. Science, 1997, 373, 230.

32. P. Badziag, W. S. Verwoerd, W. P. Ellis and N. R. Greiner, Nature, 1990, 343, 244.

33. J. Y. Raty and G. Galli, Nature Mater., 2003, 2, 792.

34. S. T. Lee, H. Y. Peng, X. T. Zhou, N. Wang, C. S. Lee, I. Bello and Y. Lifshitz, Science, 2000, 287, 104.

35. S. Pecoraro, J. C. Arnault and J. Werckmann, Diam. Relat. Mater., 2004, 13, 342 .

36. D. Wittorf, W. Jager, C. Dieker, A. Floter and H. Guttler, Diam. Relat. Mater., 2000, 9, 1696.

37. Y. Lifshitz, X. M. Meng, S. T. Lee, R. Akhveldiany and A. Hoffman, Phys. Rev. Lett., 2004, 93, 056101.

38. R. Brescia, M. Schreck, S. Gsell, M. Fischer and B. Stritzker, Diam. Relat. Mater., 2008, 17, 1047.

39. S. Kono, M. Shiraishi, N. I. Plusnin, T. Goto, Y. Ikehima, T. Abukawa, M. Schimomura, Z. Dai, C. Bernarski-Meinke and B. Golding, New Diamond and Frontier Carbon Technology, 2005, 15, 363.

40. S. Gsell, S. Berner, T. Brugger, M. Schreck, R. Brescia, M. Fischer, T. Greber, J. Osterwalder and B. Stritzker, Diam. Relat. Mater., 2008, 17, 1029. 
41. A. Hoffman, Sh. Michaelson, R. Akhvlediani, N. K. Hangaly, S. Gsell, R. Brescia, M. Schreck, B. Stritzker, J. C. Arnault and S. Saada, Phys. Stat. Solidi, 2009, 206, 1972.

42. D. Das and R. N. Singh, Inter Mqter. Reviews, 2007, 52, 29.

43. M. Schreck in Heteroepitaxid Dowth in CVD Diamond for Electronic Devices and Sensors, ed. Ricardo S. Sussmann, 2009, John Wiley \& Sons.

44. J. C. Arnault, Surf. Rev. Lett., 2003, 10, 127.

45. S. Saada, J. C. Arnault, N. Tranchant, M. Bonnauron and P. Bergonzo, Phys. Stat. Sol., 2007, 204, 2854.

46. T. B. Massalski, H. Okamoto, P. R. Subramanian, L. Kacprzak (eds), Binary Alloy Phase Diagramms, vol. 1, ASM International, Materials Park, $\mathrm{OH}, 1990$, p. 871.

47. D. N. Belton and S. J. Schmieg, Thin Solid Films, 1992, 212, 68.

48. A. Lindlbauer, R. Haubner and B. Lux, Diam. Films Technol., 1992, $2,81$.

49. P. C. Yang, W. Zhu and J. T. Glass, J. Mater. Res., 1993, 8, 1773.

50. T. Tachibana, Y. Yokota, K. Kobashi and Y. Shintani, J. Appl. Phys., 1997, 82, 4327.

51. T. Tachibana, Y. Yokota, K. Hayashi and K. Kobashi, Diam. Relat. Mater., 2001, 10, 1633.

52. L. Constant, C. Speisser and F. Le Normand, Surf. Science, 1997, 387, 28.

53. X. Li, W. Cai, J. An, S. Kim, J. Nah, D. Yang, R. Piner, A. Velamakanni, I. Jung, E. Tutuc, S. K. Banerjee, L. Colombo and R. S. Ruoff, Science, 2009, 324, 1312.

54. J. C. Arnault, S. Delclos, S. Saada, N. Tranchant and P. Bergonzo, J. Appl. Phys., 2007, 101, 014904.

55. J. C. Arnault, L. Intiso, S. Saada, S. Delclos, P. Bergonzo and R. Polini, Appl. Phys. Lett., 2007, 90, 044101.

56. A. Chavanne, J. C. Arnault, J. Barjon and J. Arabski, Surf. Science, 2011, 605, 564.

57. Th. Bauer, S. Gsell, F. Hormann, M. Schreck and B. Stritzker, Diam. Relat. Mater., 2004, 13, 335.

58. A. Chavanne, J. Barjon, B. Vilquin, J. Arabski and J. C. Arnault, Diam. Relat. Mater., 2012, 22, 52.

59. N. Vaissière, S. Saada, J. C. Arnault, $\beta$ Buttemy, A. Etcheberry, P. Bergonzo, Diam. Relat. Mater., 2013, Shitted.

60. J. C. Angus, A. Argoitia, R. Gat, Z. Li, M. Sunkara, L. Wang and Y. Wang, Trans. Phil. Mag., A, 1993, 342, 195.

61. W. A. Yarbrough, J. Am. Ceram. Soc., 1992, 75, 3179.

62. B. Lewis and J. C. Anderson, Nucleation and Growth of Thin Films, Academic Press, New York, 1978.

63. J. A. Venables, G. D. T. Spiller and M. Hanbücken, Rep. Progr. Phys., 1984, 47, 399.

64. Y. Bar Yam and T. D. Moustakas, Nature, 1989, 342, 786.

65. R. Ramesham and C. Ellis, J. Mat. Res., 1992, 7, 1189.

66. P. A. Dennig and D. A. Stevenson, Appl. Phys. Lett., 1991, 59, 1562. 
67. E. I. Givargizov, V. V. Zhirnov, A. V. Kuznetsov and P. S. Plekhanov, Mater. Letters, 1993, 18, 61.

68. R. Polini, J. Appl. Phys., 1992, 72, 2517.

69. K. Kobayashi, N. Mutsumura and Y. Machi, Mater. Manufacturing Processes, 1992, 7, 395.

70. R. Polini, M. Tomellini, M. Fanfoni and F. Le Normand, Surf. Science, 1997, 373, 230.

71. J. C. Arnault, S. Pecoraro, J. Werckmann and F. Le Normand, Diam. Relat. Mater., 2001, 10, 1612.

72. R. Polini, P. D’Antonio and E. Traversa, Diam. Relat. Mater., 2003, 12,340 .

73. W. S. Yang and J. H. Je, J. Mater. Research, 1996, 1, 1787.

74. K. Mitsuda, Y. Kojima, T. Yoshida and K. Akashi, J. Mater. Sci., 1987, 22, 1557.

75. P. E. Pehrsson, F. G. Celii, J. E. Butler, in Diamond Films and Coatings, ed. R. F. Davis, Noyes Publications, Park Ridge, 1993, p. 68.

76. S. Iijima, Y. Aikawa and K. Baba, Appl. Phys. Lett., 1990, 57, 2646.

77. P. Ascarelli and S. Fontana, Appl. Surf. Science, 1993, 64, 307.

78. B. Lux and R. Haubner, in Diamond and Diamond-like Films and Coatings, R. E. Clausing et al. (eds), 1991, New York, Plenum Press, pp. 579-609.

79. J. C. Arnault, L. Demuynck, C. Speisser and F. Le Normand, Europ. Phys. Journal B, 1999, 11, 327.

80. S. Yugo, A. Izumi, T. Kanai, T. Muto and T. Kimura, Proc. 2nd Int. Conf. New Diamond Science and Technology, 1991, Pittsburg, PA, MRS, pp. 385-389.

81. C. H. Lee, Z. D. Lin, N. G. Shang, L. S. Liao, I. Bello, N. Wang and S. T. Lee, Phys. Rev. B, 2000, 62, 17134.

82. A. A. Morrish and P. E. Pehesson, Appl. Phys. Lett., 1991, 59, 417.

83. J. Yang, X. W. Su, Q. J. Chen and Z. D. Lin, Appl. Phys. Lett., 1995, 66, 3284.

84. S. Yugo, Zumi, T. Kanai, T. Muto and T. Kimura, Proc. 2nd Int. Conf. New Did Od Science and Technology, 1991, Pittsburg, PA, MRS, pp. 385-389.

85. S. Yugo, T. Kanai, T. Kimura and T. Muto, Appl. Phys. Lett., 1991, 58, 1036.

86. B. R. Stoner, G. H. M. Ma, S. D. Wolter and J. T. Glass, Phys. Rev. B, 1992, 45, 11067.

87. X. Jiang and C. P. Klages, Diam. Relat. Mater., 1993, 2, 1112.

88. F. Stubhan, M. Ferguson, H.-J. Füsser and R. J. Behm, Appl. Phys. Lett., 1995, 66, 1900.

89. Q. Chen, J. Yang and Z. Lin, Appl Phys. Lett., 1995, 67, 1853.

90. X. T. Zhou, H. L. Lai, H. Y. Peng, C. Sun, W. J. Zhang, N. Wang, I. Bello, C. S. Lee and S. T. Lee, Diam. Relat. Mater., 2000, 9, 134.

91. S. D. Wolter, T. H. Borst, A. Vescan and E. Kohn, Appl. Phys. Lett., 1996, $68,3558$. 
92. A. Flöter, H. Güttler, G. Schulz, D. Steinbach, C. Lutz-Elsner, R. Zachai, A. Bergmaier and G. Dollinger, Diam. Relat. Mater., 1998, 7, 283.

93. M. Katoh, M. Aoki and H. Kawarada, Jpn. J. Appl. Phys., 1994, 33, L194.

94. S.-T. Lee, Z. D. Lin and X. Jiang, Mater. Sci. Eng., 1999, 25, 123.

95. X. Jiang, K. Schiffmann, C. P. Klages, D. Wittorf, C. L. Jia, K. Urban and W. Jaeger, J. Appl. Phys., 1998, 83, 2511.

96. H. Kawarada, C. Wild, N. Herres, R. Locher and P. Koidl, J. Appl. Phys., 1997, 81, 3490.

97. M. Schreck, F. Hörmann, H. Roll, T. Bauer and B. Stritzker, New Diamond and Frontier Carbon Technology, 2001, 11, 189.

98. K Hassouni, F Silva and A Gicquel, J. Phys. D: Appl. Phys., 2010, 43, 153001.

99. M. Schreck, T. Bauer and B. Stritzker, Diam. Relat. Mater., 1995, 4, 553.

100. S. Kátai, Z. Tass, G. Hars and P. Deak, J. Appl. Phys., 1999, 86, 5549.

101. S. Kátai, A. Kováts, I. Maros and P. Deák, Diam. Relat. Mater., 2000, 9, 317.

102. S. Barrat, S. Saada, J. M. Thiebaut and E. Bauer-Grosse, Diam. Relat. Mater., 2001, 10, 1637.

103. A. Guise, S. Barrat and E. Bauer-Grosse, Diam. Relat. Mater., 2007, 16, 695.

104. C. Sarrieu, N. Barth, A. Guise, J. C. Arnault, S. Saada, S. Barrat and E. Bauer-Grosse, Phys. Stat. Sol. (A), 2009, 206, 1967.

105. X. Jiang, K. Schiffmann and C. P. Klages, Phys. Rev. B, 1994, 50, 8402.

106. T. Bauer, S. Gsell, M. Schreck, J. Goldfuß, J. Lettieri, D. G. Schlom and B. Stritzker, Diam. Relat. Mater., 2005, 14, 314.

107. C. Bednarski, Z. Dai, A. P. Li and B. Golding, Diam. Relat. Mater., 2003, $12,241$.

108. T. Aoyama, N. Amano, T. Goto, T. Abukawa, S. Kono, Y. Ando and A. Sawabe, Diam. Relat. Mater., 2007, 16, 594.

109. J. C. Arnault, S. Saada, S. Delclos, S. Pecoraro, P. Bergonzo, Mater. Res. Soc. Symp. Proc. 2008, Warrendale, PA, 1039.

110. J. Gerber, S. Sattel, K. Jung, H. Ehrhard and J. Robertson, Diam. Relat. Mater., 1995, 4, 559.

111. Y. Lifshitz, T. Kohler, T. Frauenheim, I. Guzmann, A. Hoffman, R. Q. Zhang, X. T. Zhou and S. T. Lee, Science, 2002, 297, 1531.

112. S. Sattel, J. Gerber and H. Ehrhardt, Phys. Status Solidi A, 1996, 154, 141.

113. X. Jiang, K. Schiffmann and C. P. Klages, Phys. Rev. B, 1994, 50, 8402.

114. K. G. Perng, K. S. Liu and I. N. Lin, Appl. Phys. Lett., 2001, 79, 3257.

115. T. Suesada, N. Nakamura, H. Nagasawa and H. Kawarada, Jap. J. Appl. Phys., 1995, 34, 4898.

116. J. C. Arnault, S. Saada, S. Delclos, L. Intiso, N. Tranchant, R. Polini and P. Bergonzo, Diam. Relat. Mater., 2007, 16, 690-694.

117. T. Bauer, S. Gsell, F. Hormann, M. Schreck and B. Stritzker, Diam. Relat. Mater., 2004, 13, 335.

118. S. Koizumi and T. Inuzuka, Jpn J. Appl. Phys., 1993, 32, 3920. 
119. M. Fischer, S. Gsell, M. Schreck, R. Brescia and B. Stritzker, Diam. Relat. Mater., 2008, 17, 1035.

120. M. Schreck, Th. Bauer, S. Gsell, F. Hörmann, H. Bielefeldt and B. Stritzker, Diam. Relat. Mater., 2003, 12, 262.

121. B. Golding, C. Bednarski-Meinke and Z. Dai, Diam. Relat. Mater., 2004, 13, 545.

122. N. Jiang, B. W. Sun, Z. Zhang and Z. Lin, J. Mater. Res., 1994, 9, 2695.

123. X. Jiang, K. Schiffmann and C.-P. Klages, Physical Review B, 1994, 50, 8402 .

124. K. Suzuki, A. Sawabe, H. Yasuda and T. Inuzuka, Applied Physics Letters, 1987, 50, 728.

125. H. Liu and D. S. Dandy, Diamond and Related Materials, 1995, 4, 1173.

126. S.-T. Lee, Z. Lin and X. Jiang, Materials Science and Engineering: $R$ : Reports, 1999, 25, 123.

127. S. Iijima, Y. Aikawa and K. Baba, J. Mater. Res., 1991, 6, 1491.

128. W. S. Yang and J. H. Je, J. Mater. Res., 1996, 11, 1787.

129. C.-P. Chang, D. L. Flamm, D. E. Ibbotson and J. A. Mucha, J. Appl. Phys., 1988, 63, 1744.

130. B. V. Spitsyn, L. L. Bouilov and B. V. Derjaguin, J.Cryst. Growth, 1981, 52, 219.

131. P. A. Dennig and D. A. Stevenson, Appl. Phys. Lett., 1991, 59, 1562.

132. R. Akhvlediani, I. Lior, S. Michaelson and A. Hoffman, Diamond and Related Materials, 2002, 11, 545.

133. M. Varga, T. Ižák, A. Kromka, M. Veselý, K. Hruška and M. Michalka, Central European J. Phys., 2011, 10, 218.

134. O. A. Shenderova, V. V. Zhirnov and D. W. Brenner, Critical Rev. Solid State Mater. Sci., 2002, 27, 227.

135. K. Niwase, T. Tanaka, Y. Kakimoto, K. N. Ishihara and P. H. Shingu, Mater. Trans. JIM, 1995, 36, 282.

136. A. Krueger, Adv. Mater., 2008, 20, 2445.

137. M. Ozawa, M. Inaguma, M. Takahashi, F. Kataoka, A. Krueger and E. Osawa, Adv. Mater., 2007, 19, 1201.

138. A. Krueger, F. Kataoka, M. Ozawa, T. Fujino, Y. Suzuki, A. E. Aleksenskii, A. Y. Vul' and E. Osawa, Carbon, 2005, 43, 1722.

139. S. Osswald, G. Yushin, V. Mochalin, S. O. Kucheyev and Y. Gogotsi, J. Am. Chem. Soc., 2006, 128, 11635.

140. A. M. Schrand, S. A. C. Hens and O. A. Shenderova, Critical Rev. Solid State Mater. Sci., 2009, 34, 18.

141. A. Krueger, Y. Liang, G. Jarre and J. Stegk, J. Mater. Chem., 2006, 16, 2322.

142. T. Petit, J. C. Arnault, H. A. Girard, M. Sennour, T.-Y. Kang, C.-L. Cheng and P. Bergonzo, Nanoscale, 2012, 4, 6792.

143. O. A. Williams, J. Hees, C. Dieker, W. Jäger, L. Kirste, and C. E. Nebel, ACS Nano, 2010, 4, 4824.

144. O. Shenderova, S. Hens and G. McGuire, Diamond and Related Materials, 2010, 19, 260. 
145. J. C. Arnault, S. Saada, O. A. Williams, K. Haenen, P. Bergonzo, M. Nesladek, R. Polini and E. Osawa, Phys. Stat. Sol. (A), 2008, 205, 2108.

146. M. Amaral, F. Almeida, A. J. S. Fernandes, F. M. Costa, F. J. Oliveira and R. F. Silva, Surface Coatings Technol., 2010, 204, 3585.

147. T. Hartnett, R. Miller, D. Montanari, C. Willingham and R. Tustison, J. Vacuum Sci. Technol. A, 1990, 8, 2129.

148. D. Varshney, A. Kumar, M. J.-F. Guinel, B. R. Weiner and G. Morell, Diamond and Related Materials, 2012, 21, 99.

149. A. V. Sumant, P. U. P. A. Gilbert, D. S. Grierson, A. R. Konicek, M. Abrecht, J. E. Butler, T. Feygelson, S. S. Rotter and R. W. Carpick, Diamond and Related Materials, 2007, 16, 718.

150. K. Hanada, K. Matsuzaki and T. Sano, Surface Science, 2007, 601, 4502.

151. A. Bongrain, E. Scorsone, L. Rousseau, G. Lissorgues, C. Gesset, S. Saada and P. Bergonzo, J. Micromech. Microeng., 2009, 19, 74015.

152. E. Scorsone, S. Saada, J. C. Arnault and P. Bergonzo, J. Appl. Phys., 2009, 106, 14908.

153. A. Kromka, O. Babchenko, H. Kozak, K. Hruska, B. Rezek, M. Ledinsky, J. Potmesil, M. Michalka and M. Vanecek, Diamond Relat. Mater., 2009, 18, 734 .

154. O. A. Williams, O. Douhret, M. Daenen, K. Haenen, E. Osawa and M. Takahashi, Chem. Phys. Lett., 2007, 445, 255.

155. V. V. Danilenko, Phys. Solid State, 2004, 46, 595.

156. A. Kromka, B. Rezek, Z. Remes, M. Michalka, M. Ledinsky, J. Zemek, J. Potmesil and M. Vanecek, Chem. Vap. Deposition, 2008, 14, 181.

157. L. Ondic, K. Dohnalova, M. Ledinsky, A. Kromka, O. Babchenko and B. Rezek, ACS Nano, 2011, 5, 346.

158. S. C. Hens, G. Cunningham, T. Tyler, S. Moseenkov, V. Kuznetsov and O. Shenderova, Diamond and Related Materials, 2008, 17, 1858.

159. A. Kromka, O. Babchenko, H. Kozak, K. Hruska, B. Rezek, M. Ledinsky, J. Potmesil, M. Michalka and M. Vanecek, Diamond Relat. Mater., 2009, 18, 734 .

160. I. Zhitomirsky, Materials Letters, 1998, 37, 72.

161. A. N. Alimova, N. N. Chubun, P. I. Belobrov, P. Y. Detkov, and V. V. Zhirnov, in Papers from the 11th International Vacuum Microelectronics Conference, AVS, Asheville, North Carolina (USA), 1999, vol. 17, p. 715.

162. A. Mamedov, J. Ostrander, F. Aliev and N. A. Kotov, Langmuir, 2000, 16, 3941.

163. W. Xue and T. Cui, Nanotechnology, 2007, 18, 145709.

164. S.-K. Lee, J.-H. Kim, M.-G. Jeong, M.-J. Song and D.-S. Lim, Nanotechnology, 2010, 21, 505302.

165. H. a. Girard, E. Scorsone, S. Saada, C. Gesset, J. C. Arnault, S. Perruchas, L. Rousseau, S. David, V. Pichot, D. Spitzer and P. Bergonzo, Diamond and Related Materials, 2012, 23, 83.

166. H. A. Girard, S. Perruchas, C. Gesset, M. Chaigneau, L. Vieille, J.-C. Arnault, P. Bergonzo, J.-P. Boilot and T. Gacoin, ACS Appl. Mater. Interfaces, 2009, 1, 2738. 
167. E. Chevallier, E. Scorsone, H. A. Girard, V. Pichot, D. Spitzer and P. Bergonzo, Sensors Actuators B, 2010, 151, 191.

168. J. H. Kim, S. K. Lee, O. M. Kwon, S. I. Hong and D. S. Lim, Diamond Relat. Mater., 2009, 18, 1218.

169. H. Masuda, M. Watanabe, K. Yasui, D. Tryk, T. Rao and A. Fujishima, Advanced Materials, 2000, 12, 444.

170. N. Yang, H. Uetsuka, E. Osawa and C. E. Nebel, Nano Letters, 2008, 8, 3572 .

171. T. M. Babinec, B. J. M. Hausmann, M. Khan, Y. Zhang, J. R. Maze, P. R. Hemmer and M. Loncar, Nature Nanotechnology, 2010, 5, 195.

172. X. Checoury, D. Néel, P. Boucaud, C. Gesset, H. Girard, S. Saada and P. Bergonzo, Applied Physics Letters, 2012, 101, 171115.

173. H. L. and C. W. and C. G. and Y. H. and J. L. and G. Z. and C. Wen, J. Physics: Condensed Matter, 2002, 14, 10973.

174. A. Bongrain, E. Scorsone, L. Rousseau, G. Lissorgues and P. Bergonzo, Sensors Actuators B, 2011, 154, 142.

175. O. Babchenko, E. Verveniotis, K. Hruska, M. Ledinsky, A. Kromka and B. Rezek, Vacuum, 2012, 86, 693.

176. A. Kromka, O. Babchenko, B. Rezek, M. Ledinsky, K. Hruska, J. Potmesil and M. Vanecek, Thin Solid Films, 2009, 518, 343.

177. N. A. Fox, M. J. Youh, J. W. Steeds and W. N. Wang, J. Appl. Phys., 2000, 87, 8187.

178. H. Zhuang, B. Song, T. Staedler and X. Jiang, Langmuir, 2011, 27, 11981.

179. Y. C. Lee, S. J. Lin, C. Y. Lin, M. C. Yip, W. Fang and I. N. Lin, Diam. Relat. Mater., 2006, 15, 2046.

180. M. Bonnauron, S. Saada, L. Rousseau, G. Lissorgues, C. Mer and P. Bergonzo, Diam. Relat. Mater., 2008, 17, 1399. 